\title{
Stadium City: A Modern Re-imagination of the Sports complex
}

by

Erick Hyun Yong Kim

A thesis submitted to the Faculty of Graduate and Postdoctoral Affairs in partial fulfillment of the requirements for the degree of

Master of Architecture

in

Azrieli school of Architecture

Carleton University

Ottawa, Ontario

C 2017, Erick Hyun Yong Kim 


\begin{abstract}
Sport can unify cities and people in unique ways. From pick-up games in neighbourhoods and parks, to amateur leagues and professional spectacles, public sporting events can build and strengthen the collective civic pride and solidarity of a city. Cities, as a result, invest millions of dollars in building stadiums for major sporting events such as the Olympics and for various sporting leagues at all levels - from the amateur to the professional. While these stadiums are often lively during sporting events, the can often sit abandoned when these games stop or when sporting seasons are over. Rarely open to the public, these stadiums stay empty and their potential use is never fully realised. This thesis re-imagines the urban stadium as a multi-sport facility that is inviting to the inhabitants of the city. The thesis concentrates on the design of a single, multipurpose sports building located in Toronto. This stadium acts as a node within a multifunctional "world of sport" which is open to the public and promotes healthy activities and civic belonging.
\end{abstract}




\section{Acknowledgements}

Thanks to my lord, who is always watching me and listens my prayer and thanks to my family for their love and support.

It is a great pleasure to acknowledge my deepest thanks and gratitude to Prof. Inderbir Singh Riar, professor of Architecture, Faculty of Azrieli school of Architecture Carleton University, for suggesting the direction of this thesis, and his kind supervision. It is a great honour to work under his supervision.

I would like to express my deepest thanks and sincere appreciation to Prof. Ozayr Saloojee, professor of Architecture, Faculty of Azrieli school of Architecture Carleton University, for his encouragement, creative and comprehensive advice until this work came to existence.

Erick Hyun Yong Kim

December 2017 


\section{Table of Contents}

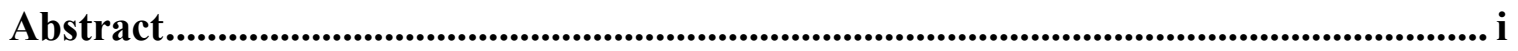

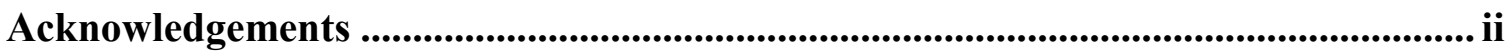

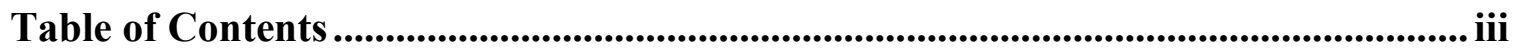

List of Figures.................................................................................................................. iv

1 Chapter: General Introduction + Site Analysis.......................................................... 1

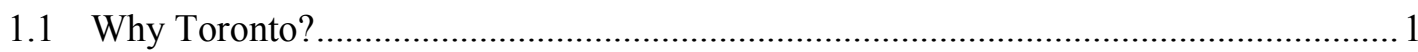

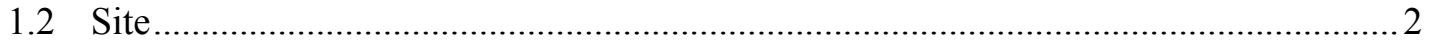

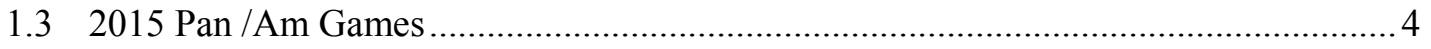

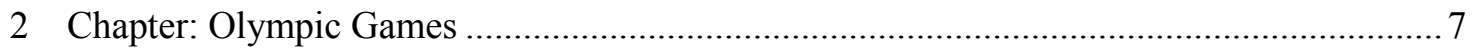

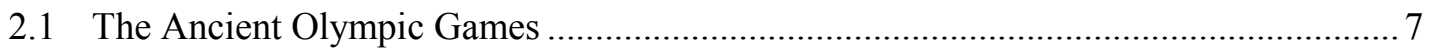

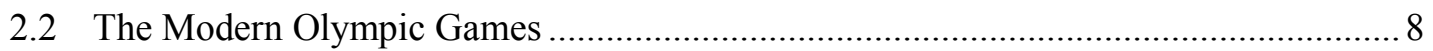

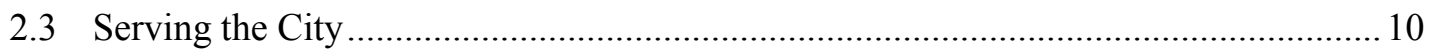

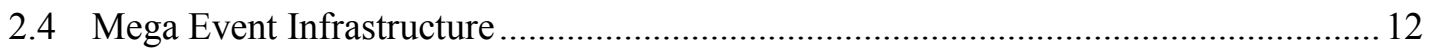

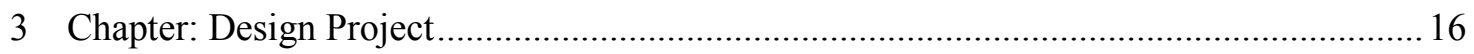

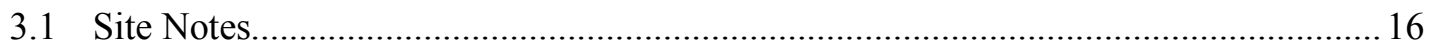

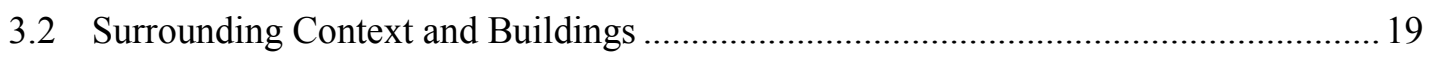

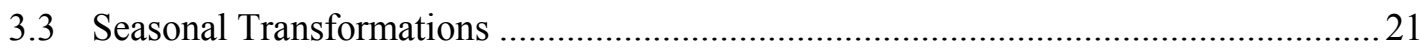

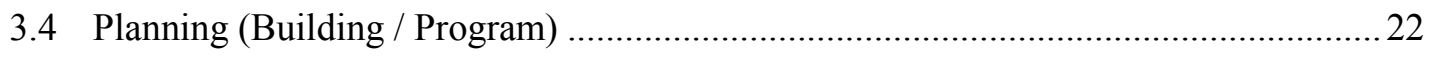

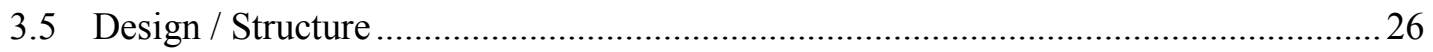

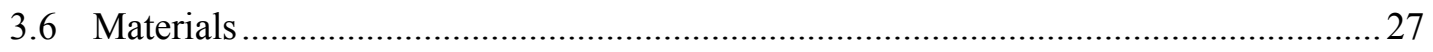

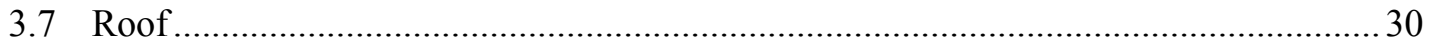

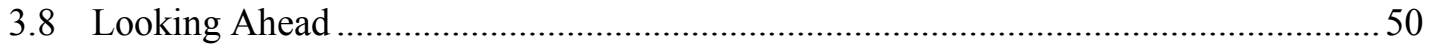

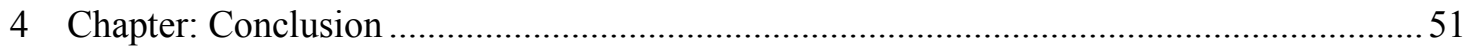

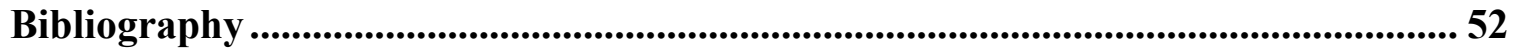




\section{List of Figures}

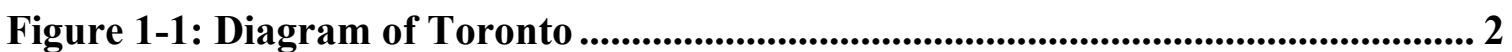

Illustrated by author

Figure 1-2: Existing Condition of the site (Final image to be insert) .......................... 3

Illustrated by author

Figure 1-3: Exhibition Place 2015 Toronto Pan Am Venues ....................................... 4

Illustrated by author

Figure 1-4: Four key words model opens up to world..............................................6 6

Photo by author

Figure 2-1: Plan of Olympia (Temple of Zeus) .................................................... 8

Swaddling, J. (2008). Plan of Olympia [plan]. The ancient Olympic games, $2^{\text {nd }}$ ed.. Austin: University of Texas Press, P. 14.

Figure 3-1: Public Transit .................................................................................. 17

Illustrated by author

Figure 3-2: Walkway path.......................................................................................... 18

Illustrated by author 


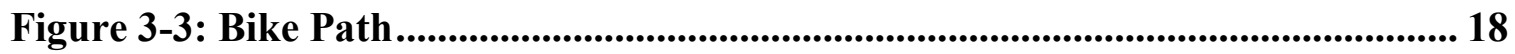

Illustrated by author

Figure 3-4: BMO Field Stadium .................................................................................. 20

Photo by author

Figure 3-5: Coca-Cola Coliseum....................................................................................... 20

Photo by author

Figure 3-6: Enercare Centre ................................................................................................ 21

Photo by author

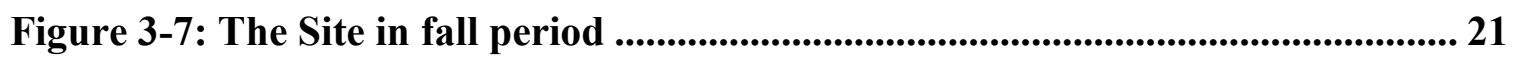

Photo by author

Figure 3-8: The Site in summer period ...................................................................... 22

Photo by author

Figure 3-9: 2015 Pan Am Game venues to proposed idea............................................ 24

Illustrated by author

Figure 3-10: Proposed project in the site .............................................................. 24

Illustrated by author 
Figure 3-11: Proposed project with new circulation through the site.

Illustrated by author

Figure 3-12: Flowing water concept ............................................................................. 27

Created / photo by author

Figure 3-13: Precedent-Centre Pompidou, Metz

Shigeru-ban-centre-pompidou-metz_pleatfarm-7. (2011). Site usage in, 2015.

https:/gatewaytoecclesallwoods.wordpress.com/2011/10/06/influences-part-1/shigeruban-centre-pompidou-metz_pleatfarm-7/.

Figure 3-14: Precedent- Louvre, Abu-Dhabi...................................................... 29

Timelapse Reveals Eight-year Construction of Louvre Abu Dhabi. (2017). Site usage in 2017

https://www.dezeen.com/2017/11/22/timelapse-movie-reveals-eight-year-constructionlouvre-abu-dubaijean-nouvel/.

Figure 3-15: Exhibition hall 1 31

Rendered by author

Figure 3-16: Exhibition Hall 2 32

Rendered by author 
Figure 3-17: Rock Climbing facility

Rendered by author

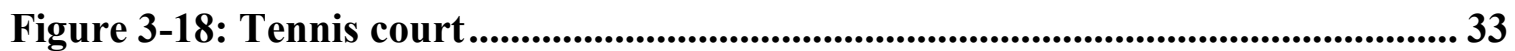

Rendered by author

Figure 3-19: Velodrome / Handball court 1

Rendered by author

Figure 3-20: Velodrome / Handball court 2

Rendered by author

Figure 3-21: New circulation corridor to the project 1

Rendered by author

Figure 3-22: New circulation corridor to the project 2

Rendered by author

Figure 3-23: New circulation corridor to the project 3

Rendered by author

Figure 3-24: Opened folding glazing winter view 36

Rendered by author 
Figure 3-25: Closed folding glazing summer view

Rendered by author

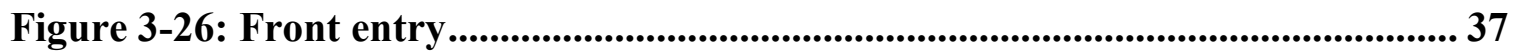

Rendered by author

Figure 3-27: Floor plan 1 .................................................................................................. 38

CAD by author

Figure 3-28: Floor plan 2 .................................................................................................. 39

CAD by author

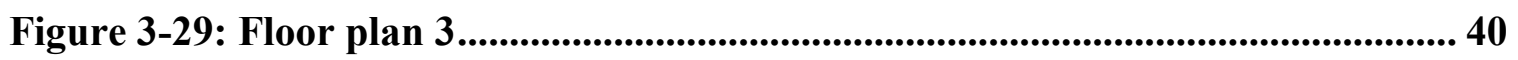

CAD by author

Figure 3-30: Floor plan 4 ......................................................................................... 41

CAD by author

Figure 3-31: Floor plan 5........................................................................................ 42

CAD by author

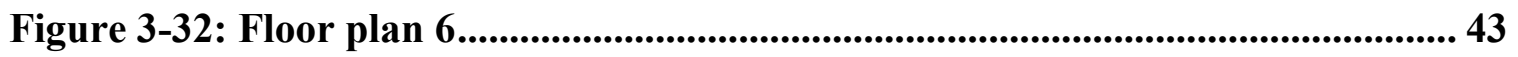

CAD by author 
Figure 3-33: Roof plan

CAD by author

Figure 3-34: Section / Elevation ....................................................................................... 45

CAD by author

Figure 3-35: Column Elevation / Section ............................................................................. 46

CAD by author

Figure 3-36: Column Plan 1 ................................................................................................ 47

CAD by author

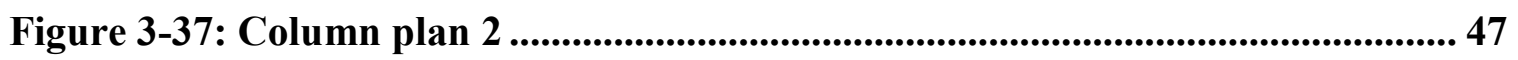

CAD by author

Figure 3-38: Column plan 3 ................................................................................... 48

CAD by author

Figure 3-39: Column detail 1 .................................................................................... 48

Rendered by author

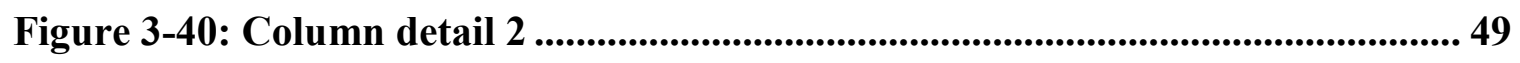

Rendered by author 
Figure 3-41: Column detail with dimension 1 .................................................... 49

CAD by author

Figure 3-42: Column detail with dimension 2 ........................................................... 50

CAD by author 


\section{Chapter: General Introduction + Site Analysis}

\subsection{Why Toronto?}

Toronto is home to 2.8 million people. It is among the most diverse of Canadian cities, the fourth largest city in North America and the largest city Canada. It is a key centre of finance, industry and culture and is considered one of the most multicultural cities in the world. Over 140 languages are spoken in the city and 30 percent of city residents speak a language other than English or French at home. Moreover, 48 percent of the total population of the city were born outside of Canada. ${ }^{1}$ With such a diverse community, the city can be viewed as a cultural mosaic.

Toronto is an excellent site for a multipurpose sports complex. The city is well known to the rest of the world for its diverse community and as Canada's largest metropolitan area. The city is an excellent representation of diversity in Canada. Likewise, world sporting mega-events, such as the Olympics, emphasize unity among competitors and spectators from the many countries of the world (Figure 1-1).

\footnotetext{
${ }^{1}$ City of Toronto. "Toronto \& the Toronto Region." Green Lane Landfill. January 03, 2017. Accessed July 10, 2017. http://www.toronto.ca/city-government/accountability-operations-customer-service/get-involvedhow-government-works/toronto-the-toronto-region/.
} 


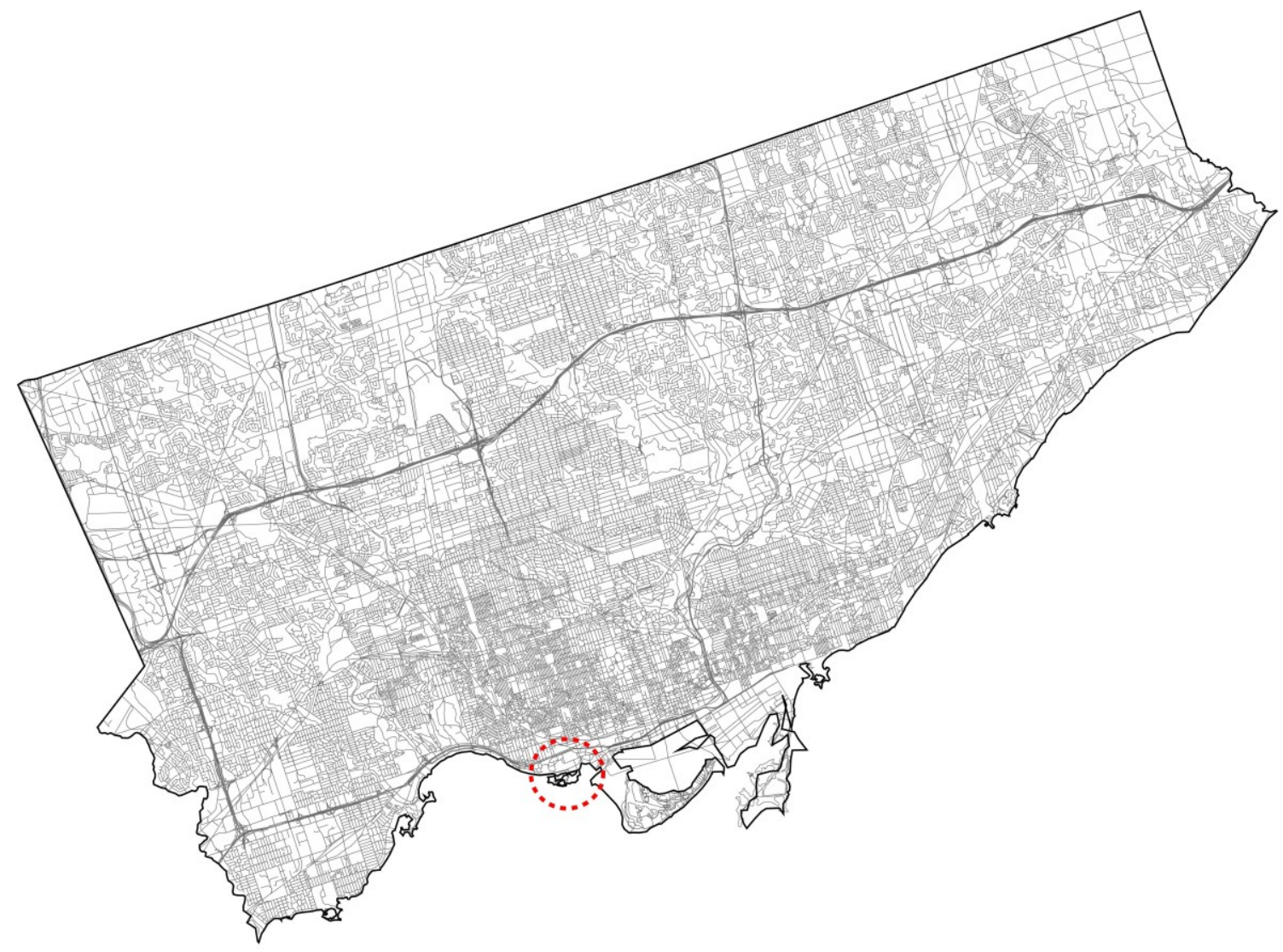

Figure 1-1: Diagram of Toronto

\subsection{Site}

The thesis project site is Exhibition Place and is located south of Toronto's downtown area, on the far western side of the Toronto Harbour Front. The Harbour Front hosts a cluster of cultural experiences and various festivals throughout the year. However, the current conditions of Exhibition Place site are limited to seasonal usage compared to rest of the Harbour Front. Exhibition Place is 260 acres $\left(1.1 \mathrm{~km}^{2}\right)$, and it includes a stadium that is currently home to the Toronto FC - the local Major League Soccer (MLS) team. ${ }^{2}$

\footnotetext{
2 "Exhibition Place." Wikipedia. May 12, 2015. Accessed November 10, 2015. https://en.wikipedia.org/wiki/Exhibition Place.
} 
The site includes cultural buildings, historical monuments and parkland. These facilities are often used for temporary exhibitions as well as public and private events. They are not only sports facilities, but could become useful modern instruments and catalysts for improving spatial and civic relations for the inhabitants of Toronto. Most of the site is occupied with vehicle parking and is poorly connected along its length. There is, however, one strong advantage to the site: its connection to the rest of the city. Walking paths and bike routes along the lakeshore make strong connections and access from both the west and east sides of Toronto. Additionally, an efficient transportation system - highway connections to the site and public transit stations - have the potential to transform this site for the better (Figure 1-2).

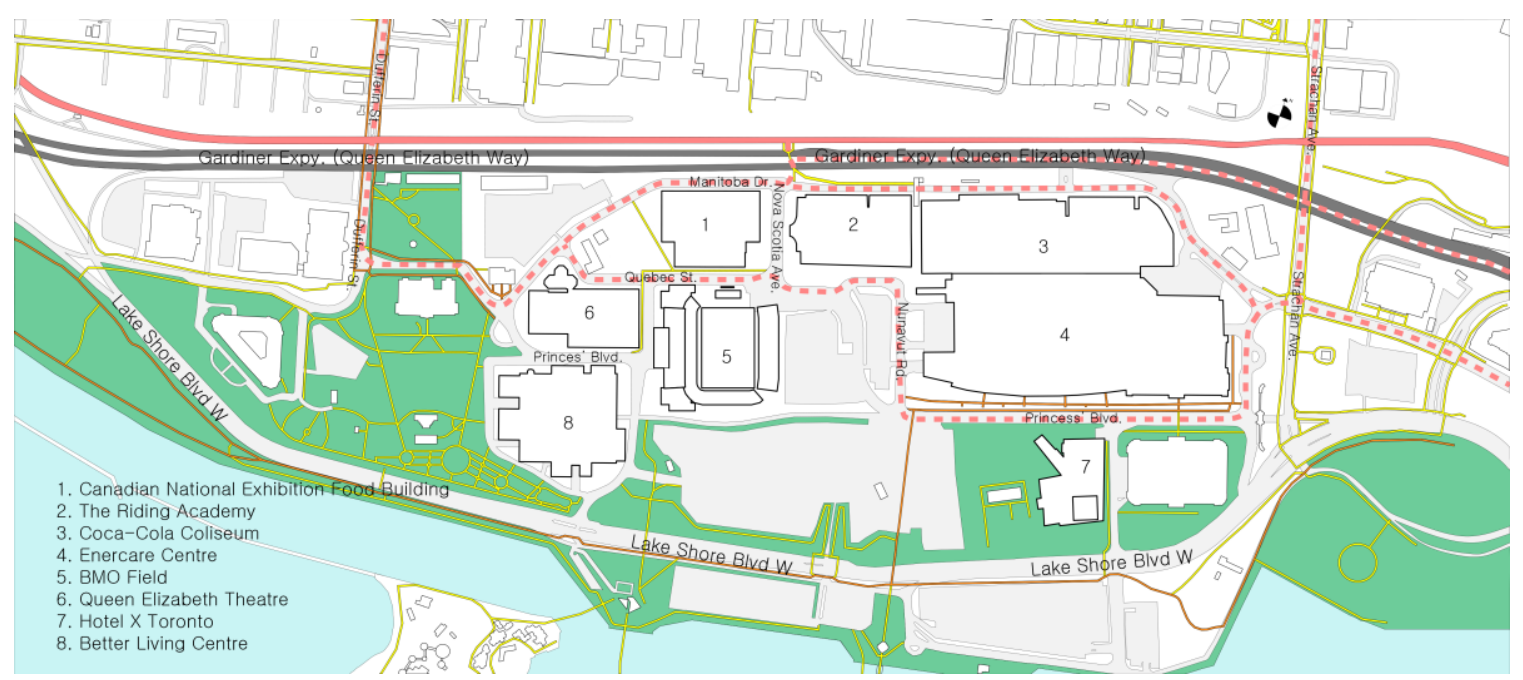

Figure 1-2: Existing Condition of the site 


\subsection{Pan /Am Games}

On November 6th 2009, the city of Toronto announced that it would host the Pan American Games, six years later, in $2015 .{ }^{3}$ Exhibition Place was selected for the event. Five competition venues and temporary cultural facilities had been built on the site. Several reasons were noted as part of the selection of Exhibition Place as a host for the games

\section{(Figure 1-3):}

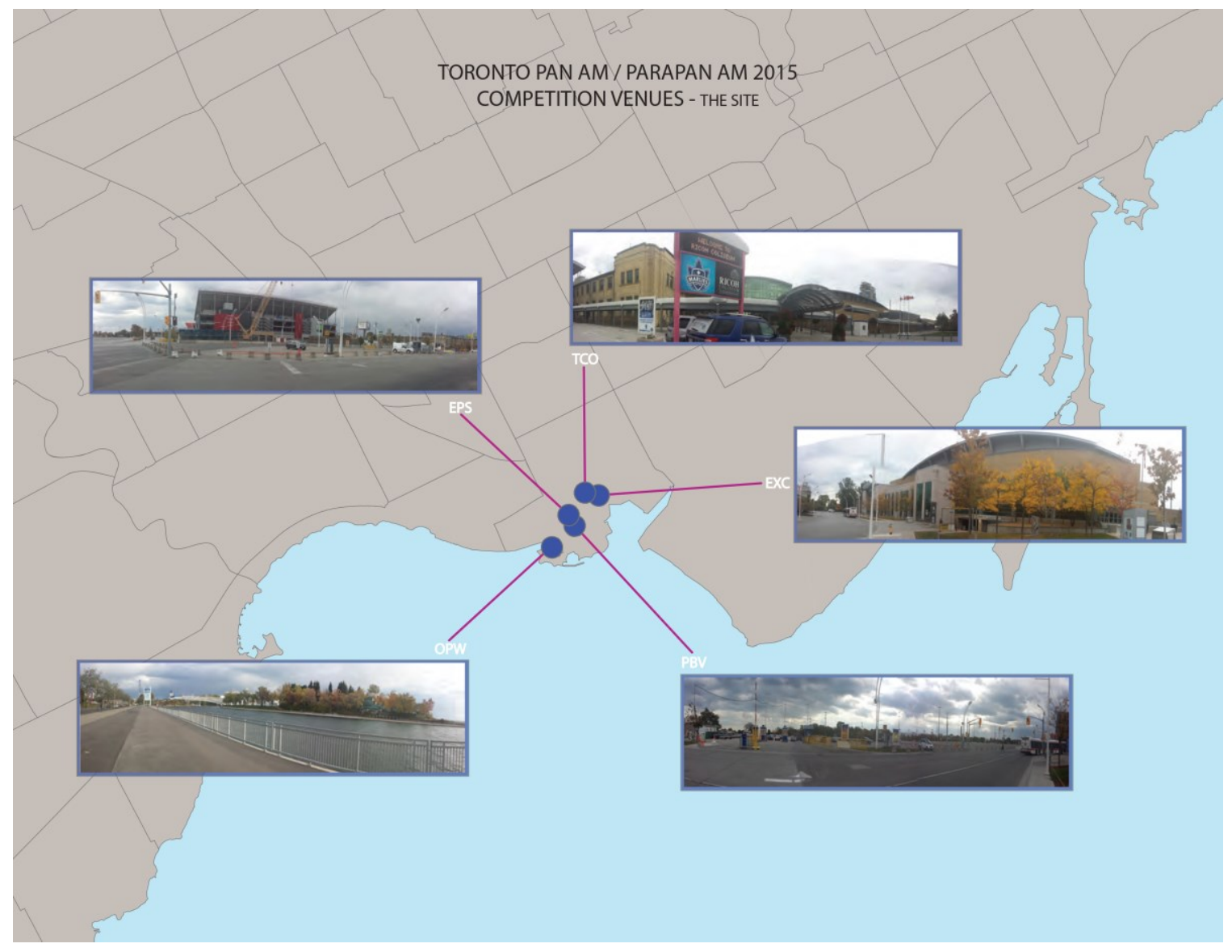

Figure 1-3: Exhibition Place 2015 Toronto Pan Am Venues

3 "About the Pan Am Games." Rowing | Toronto 2015 Pan Am / Parapan Am Games. Accessed November 5, 2015. http://www.toronto2015.org/about-us/pan-am-games. 
- Location. The site was close to open water (Lake Ontario) and the large park zones had the potential to host diverse sports activities. It was well situated downtown.

- Size. It was large enough to have more than 73,000 spectators at once in the area. Multiple and flexible programming was possible. ${ }^{4}$

- Proximity. It was close to downtown and existing, and other, Pan-Am Game venues. Most of the downtown venues were easily accessible by public transit within 30 minutes, including the athletes' dormitory.

The selection of the site the host for the 2015Pan Am / Parapan Am games in this central area confirms the potential of the site to become a centre for sports and cultural entertainment of Toronto and other satellite cities nearby. The challenge was how to fulfill a diverse sporting experience of over 29 different sporting events for a community that would come from in and outside of Toronto. The most distant venue for the event was approximately $250 \mathrm{~km}$ away from Toronto, because of the specific needs of competition sports. A modern re-imagination of the sports complex is necessary.

This thesis idea starts from four key words and design questions City, Stadium, Serve, and Inherit (Figure 1-4).

- City - a construct of various interrelating elements that plays specific role in urban life. It is driven by socio-economic forces and transforms dynamically over time.

\footnotetext{
4"Welcome to Canada's Largest Entertainment Venues." Ron Baird | Exhibition Place, Accessed November 10, 2015, www.explace.on.ca/.
} 
- Stadium - a mega-structure of today and a modern version of the Roman

colosseum. Stadia are located within the existing city and bridge the gap between urban planning and architecture.

- Serve - is a role of architecture within cities. Every architecture is formed for a particular purpose based on public demand and strategies on how to fulfill those demands.

- Inherit - the legacy of architecture over time because of transformation. An architecture might change in its original purpose in time but survives by serving new inhabitants.

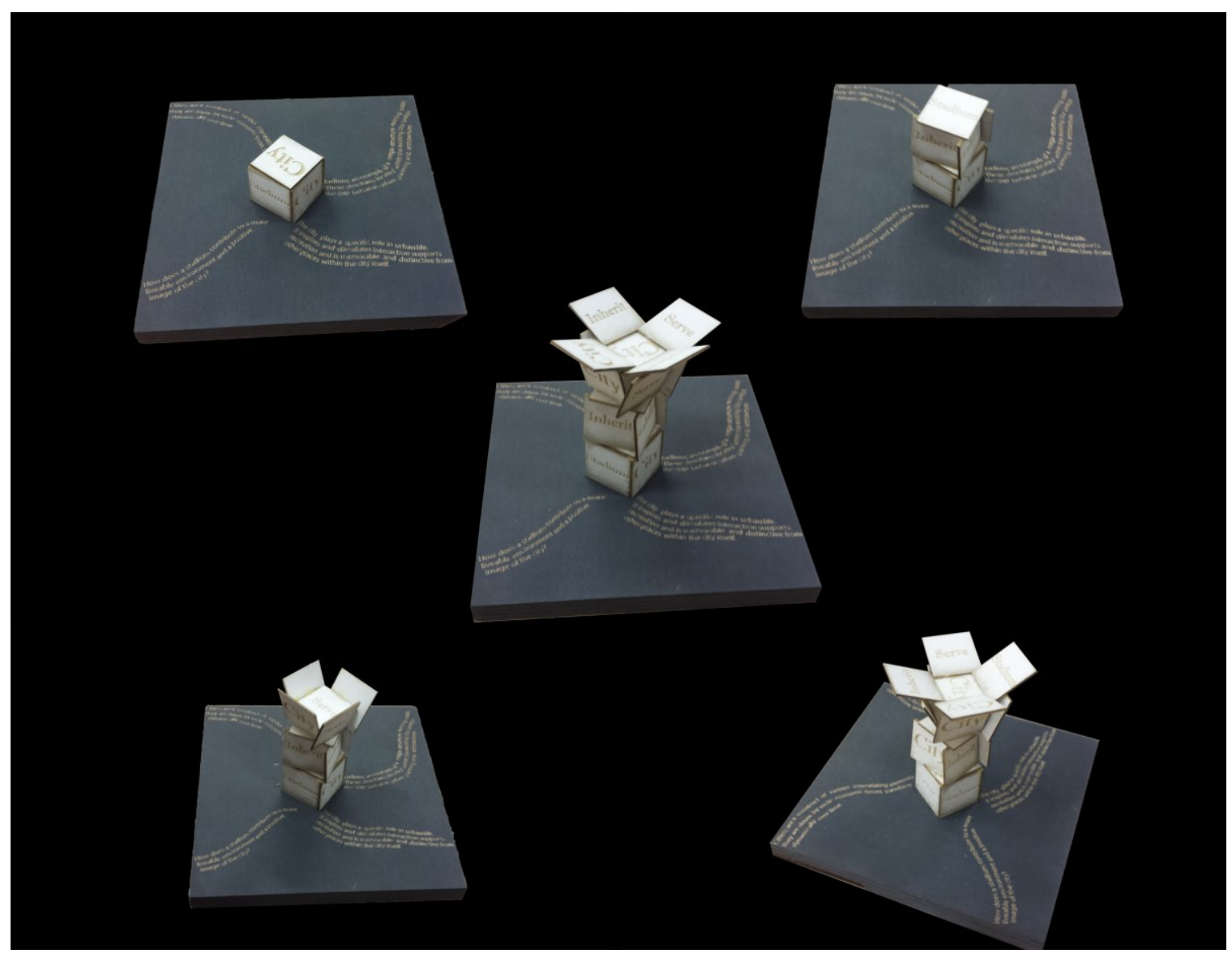

Figure 1-4: Four key words model opens up to world 
These concerns lead us to question what particular functions public facilities perform. Additionally, it asks how the inhabitants of Toronto might use these facilities used at any time? How can architects create planning strategies that address these concerns, outlining configurations for new and existing public facilities in Toronto? How does a stadium contribute to a more livable environment and a positive image of the city?

\section{Chapter: Olympic Games}

\subsection{The Ancient Olympic Games}

Globally, the most well-known sporting event is the Olympic Games. This event can be separated into two timelines. The first is referred to as the ancient Olympic Games. The ancient Olympic Games took place in Olympia, Greece from 776 B.C. to 395 A.D. and invited inhabitants from all over Greek city states and as far away as Africa and Spain. ${ }^{5}$ The Games were intended to unify the Greek people and their colonies, and to gather athletes in a host city to celebrate and acknowledge common bonds of friendship and citizenship. The selection of Olympia as the site of the games was due to the location of Zeus's temple, which was the centre of religious life in the Hellenic world and for the Hellenic communities. First developed as a cultural complex, the temple of Zeus was layered with a civic monumentality that included competition facilities (Figure 2-1).

\footnotetext{
${ }^{5}$ Swaddling, Judith. The Ancient Olympic Games. 2nd ed., Austin: University of Teas Press, 2008, 7.
} 


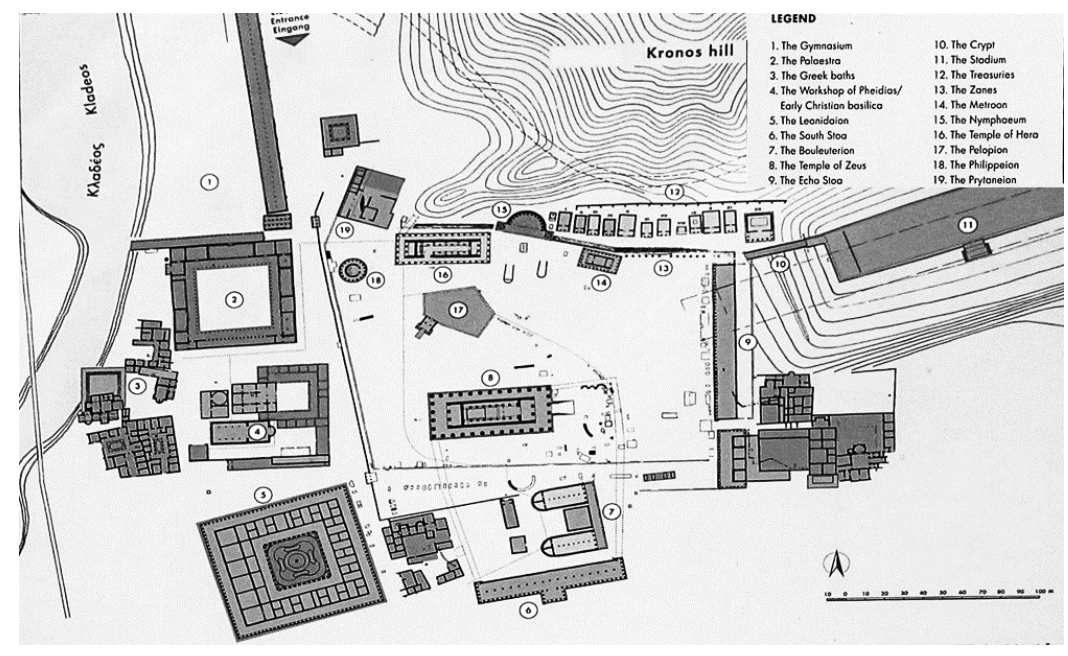

Figure 2-1: Plan of Olympia (Temple of Zeus)

Greek architects expressed much more than form and space in their designs of buildings and cities. Their architecture emphasized the hierarchy of power in the world, celebrated the democratic life of the Greek populace, and communicated a broader worldview of life beyond death: of the gods, of power, and of community. ${ }^{6}$ Greek architects created atmospheres of transcendence through the enormous scale of their architectural designs. They used light, proportion, material and high ceilings to convey solemnness and the might of the gods. Greek architecture was meant to show visitors that the Greeks were protected by the Gods and that they were indeed at the centre of the world.

\subsection{The Modern Olympic Games}

In 1896, the first modern version of the Olympic Games was revived in Athens through the efforts of a French nobleman named Baron Pierre de Coubertin. Through his

\footnotetext{
${ }^{6}$ Swaddling, Judith. The Ancient Olympic Games. 2nd ed., Austin: University of Teas Press, $2008,94$.
} 
work, 14 countries and 241 athletes joined this first international sporting event ${ }^{7}$ and the tradition of fair competition in sports and the celebration of the capabilities and capacities of the athlete continued to the latest Summer Olympic Games in Rio in 2016, where 207 countries with 11,238 athletes took part and competed in 306 different sporting events. ${ }^{8}$ At the most recent Games, the Winter Games in PyeongChang, South Korea in 2018, 92 countries participated with almost 3000 athletes in attendance. ${ }^{9}$ The main focus of these games is to exemplify sportsmanship and collegiality, diverse cultural performances and sporting competitions. Here architects are not only involved in the architectural design and construction of the sporting facilities, but they also participate in the planning of the cultural events with other design disciplines. This tradition has continued into recent history, as host cities have often placed strong importance on the development of cultural facilities as an aspect of the Games themselves.

Architects play a significant role in this context. The stadium acts as the central infrastructural element of the Olympic Games. The emphasis of sports as a unifier ties the city and its inhabitants together in diverse ways and in various public spaces and programming, including parks, pick-up games and in surrounding neighbourhoods. Often, the design of these facilities become a testing field for new architectural technologies and produce landmarks of the host cities. Stadia become emblems and cultural containers. They communicate the architects' vision for the Games and the city - and they serve as a cultural

\footnotetext{
${ }^{7}$ IOC. "Four Titles for Multi-talented Schuhmann." International Olympic Committee. February 22, 2017. Accessed June 20, 2017. https://www.olympic.org/athens-1896.

8 "Rio 2016." International Olympic Committee. September 12, 2017. Accessed February 22, 2017. https://www.olympic.org/rio-2016.

9 "PyeongChang 2018." International Olympic Committee. June 12, 2018. Accessed August 5, 2018. https://www.olympic.org/pyeongchang-2018.
} 
portrait of a host country's identity. Often, the design of these mega-structure aims to express themes of innovation as well as civic pride.

In both eras, the roles for architects in the Olympic Games remained constant. They helped transform ideas into reality and helped to showcase Olympic cities to the world. Modern architects naturally follow the foot-steps of ancient traditions and predecessors, even though the world is a remarkably different place from Ancient Greece or from de Coubertin's time. One significant change is the current trend of public architecture to respect existing surrounding elements and the sustainable inhabiting of cities. The spaces of the games are less about the fear and superiority of civic rule and religious power (as in ancient Greece). The focus has shifted, rather, to an emphasis on healthy, sustainable cities and buildings, environmental responsibility and good citizenship. ${ }^{10}$

\subsection{Serving the City}

In ancient times, grand public facilities such as stadiums or temples were representative of the physical identity of cities and symbolic power. Over time, these types of grand-scale designs began to lose value. Inhabitants desired an architecture that represented local identity and local community. In contemporary times, we see that this preference has endured - we look for buildings and architecture that make us feel connected

\footnotetext{
${ }^{10}$ Hill, Christopher R. Olympic Politics: Athens to Atlanta, 1896-1996. 2nd ed. Manchester: Manchester University Press, 1996. 35
} 
to our city's history, culture and identity, and less to ideas of spectacular monumentality. There is, increasingly, an emphasis on utility and usability as opposed to pure spectacle.

Cultural facilities such as sporting venues have risen as one of the key elements of our contemporary public spaces. ${ }^{11}$ Historically, the development of these cultural facilities and urban areas have played a significant role in city planning across the world. The processes of urban re-imagining and the development of modern urban planning has lead architects to explore the identity of new sporting venues that are increasingly more integrated into the larger urban fabric and with pre-existing urban structures. Through these processes, public facilities are no longer the sole domain of built form, but must include improvements in the quality of life in the city overall. Therefore, innovative approaches to improve urban life and to build dynamic public places have become necessary. In order to achieve these outcomes, communities need to recognize sporting venues as attractive and pleasant places while at the same time considering the context, identity and relationship these facilities have with their surroundings.

An inclusive culture is considered important in order to encourage the broad use of buildings and architectural and urban spaces. Culture as a combination of learning and leisure must guide the construction of modern public facilities. Sporting facilities can now allow city dwellers to enjoy their free time and share moments with those who have the

\footnotetext{
${ }^{11}$ Lee, Uje. Dwelling Shift. Series 348. Seoul: C3, 2013. 135
} 
same interests - and not just in sporting events. Thus, sporting venues can be regarded as landmarks within a community.

\subsection{Mega Event Infrastructure}

Since the modern Olympic Games began, the process of Olympic urbanisation has developed in many different forms for well over a century. In previous host cities with diverse urban planning patterns and cultural contexts, these events have left very different legacies and impacts in the local environment. Some of the resultant issues of the hosting of the Olympic Games still affect the development and transformation of the city decades after the event has concluded and many of the infrastructural and architectural interventions of former games are abandoned, and millions of dollars' worth of venues lie in decay. ${ }^{12}$

The integration of Olympic Games facilities into a host city's urban strategies of planning is essential to the success of the event, as well as after the conclusion of the Games themselves. Public land development influences this heavily. In the 1984 Los Angeles Olympic Games, the city deviated from the fundamental trend of Olympic Games urban development planning strategies. The central concept of this event was to create a passing Olympic moment with diverse and sustaining urban strategies rather than to generate new, massive-and likely unsustainable-urban changes. The city already possessed 24 out of 31 required facilities by using university venues and existing dormitories. ${ }^{13}$ The Los Angeles government's understanding of their city and its capacities helped avoid costly and

\footnotetext{
12 Pitts, Adrian C., and Hanwen Liao. Sustainable Olympic Design and Urban Development. Milton Park, Abingdon: Routledge, 2009. 36

${ }^{13}$ Pitts, Adrian C., and Hanwen Liao. Sustainable Olympic Design and Urban Development. Milton Park, Abingdon: Routledge, 2009. 41
} 
ultimately unnecessary, investments. Knowing the context and capacity of a city's event infrastructure is one of the most important aspects of this type of mega-event planning.

In 1992, Barcelona used the Olympic Games as an opportunity for inner city regeneration in major and central areas at a strategic moment in the city's transformation, even though the city, in fact, was considered to be in a state of post-industrial decline. ${ }^{14}$ The city's urban regeneration development throughout the preparation for the Olympic Games, and the decaying industrial and waterfront district that had separated the city's local neighbourhoods, were rehabilitated with brand new water-front cultural amenities. Specific areas were developed with well-timed interventions, through thoughtful urban planning, which emphasised local neighbourhoods and connections with locals and visitors. The Barcelona Olympic Games were both the symbolic achievements of the Olympic spirit and an engaging way to integrate planning, smartly conceptualised design execution and local engagement.

When the Olympic Games returned to Athens in 2004, the city wanted to use similar strategies as deployed in the Barcelona Olympic Games. In the beginning, this was moderately successful. However, the International Olympic Committee's (IOC) intervention in the process and the change of government in Athens, lead to a crisis in the development planning strategies. The budget was overrun. It is fair to say that the Olympics

\footnotetext{
${ }^{14}$ Pitts, Adrian C., and Hanwen Liao. Sustainable Olympic Design and Urban Development. Milton Park, Abingdon: Routledge, 2009. 38
} 
have been disastrous for the city of Athens: 21 out of 22 Olympic facilities have been not used in a long time, and they remain inaccessible to the public. ${ }^{15}$

The 2008 Beijing Olympics, in contrast, were different from other Olympic Games. The event was considered a commercial success and brought in over \$146 million dollars in profit. ${ }^{16}$ Some of the Olympic facilities, following the conclusion of the games, were like Athens and many other Olympic cities: abandoned after use. This was not as extensive as Athens was in 2004, but the city still struggled with how to use some of the facilities. Like all Olympics, Beijing used the event to raise the city's international reputation and to mitigate environmental problems with cloud seeding to control smog and pollution. ${ }^{17}$ Additionally, the city did not follow the proposed master urban development planning that was presented during the bid for the games. They drew criticism from the media and international community for not fully addressing social inequity and imbalance.

On September $8^{\text {th }} 2015$, Toronto mayor John Tory confirmed that Toronto was out of contention for hosting the 2024 summer Olympic Games. He observed,

I cannot look people in the eye at this point in our city's development and tell them that an Olympic bid is the best use of our time or our energy or our investment. I believe one-day Toronto will be a great venue for the Olympic Games but not in 2024. Let me be clear - I am not saying no to the Olympics, I am saying not this time. If we decide

\footnotetext{
${ }^{15}$ CNBC. "Olympic Cities: Booms and Busts." CNBC. July 16, 2012. Accessed July/August 2016. https://www.cnbc.com/2012/01/19/Olympic-Cities:-Booms-and-Busts.html.

${ }_{16}$ Pitts, Adrian C., and Hanwen Liao. Sustainable Olympic Design and Urban Development. Milton Park, Abingdon: Routledge, 2009. 206

${ }^{17}$ Coonan, Clifford. "How Beijing Used Rockets to Keep Opening Ceremony Dry." The Independent. October 22, 2011. Accessed August, 2016. https:/www.independent.co.uk/sport/olympics/how-beijing-used-rockets-to-keep-opening-ceremony-dry890294.html.
} 
to compete we will do it right, we will prepare, and council will make the decision together. ${ }^{18}$

The reason behind this decision was the uncertain future use of the of Pan Am Game facilities, in addition to the other necessary tasks involved, including the expansion of housing and transit. Toronto held the Pan Am Games in the summer of 2015, and while they built sufficient facilities, however, they have not found a way to use the Pan Am facilities efficiently following the event. They city's idea is that instead of using the opportunity of the Olympic Games to transform the city, look rather for other international hosting opportunities to determine a solution for these immediate facilities and to redevelop them in a more strategic and sustainable fashion. If Toronto were to host the Olympic Games, the bid would cost $\$ 50-60$ million, and $\$ 3.3$ to $\$ 7$ billion would be required for hosting the games according to a municipal study. ${ }^{19}$

This is a massive debt-burden to the inhabitants of the city (and to Canadian around the country) who do not want to be responsible for a huge tax bill. The city government was considering whether the city can bid and host. Both Los Angeles and Barcelona have been able to make substantial gains because of the nature of their planning. Barcelona improved its image on the world stage after decades of dictatorship rule. Los Angeles used existing facilities instead of constructing brand new facilities. These two cases - and their best practices - are still relevant and apply in today's environment. Many of the previous host cities won their bid by celebrating advances in building and environmental technology.

\footnotetext{
18 Rider, David. "No Olympics, but Tory Open to Other International Events." Thestar.com. September 15 , 2015. Accessed December 13, 2016. https://www.thestar.com/news/city hall/2015/09/15/its-officialtoronto-wont-bid-for-2024-olympics.html.

19 "Toronto's Possible Olympics Bid Met with Budget Cautions." Sportsnet.ca. Accessed December 15, 2016. https://www.sportsnet.ca/more/torontos-possible-olympic-bid-met-with-budget-cautions/.
} 
However, as investment costs have increased, urban planning for the Olympic Games must be focused on the inhabitants of the city and their existing infrastructure rather than solely focusing on mega-structures.

\section{Chapter: Design Project}

\subsection{Site Notes}

This thesis project proposes that Exhibition Place be re-designed as a central sports hub for the city of Toronto, and will focus primarily on the design of a large, multi-sport venue building in the larger complex of the site. The design project does not focus on the large urban development of the project, but on a single building.

The site for this design project is the Exhibition Place site located southwest of Toronto. The site can be accessed through various ways.

- Public Transit: Both Go-Train regional transit services from the western end of Lake Ontario and Toronto Transit Commission streetcar and bus operations service access to the to the site ( Figure 3-1).

- Pedestrian: There are direct sidewalk connections from downtown of Toronto and the surrounding residential area is connecting to Exhibition place as well as circulating around each building and the parks on the grounds (Figure 3-2). 
- Bicycle: There are major bike path trail connections from Harbour front in Toronto and from west to east through Exhibition place (Figure 3-3).

- Automobile: The QEW (Queen Elizabeth Way) highway is a major local highway very close to the site.

- Parking: Exhibition place offers a total of, at present, 7,750 parking spaces on ground and below-ground level in surrounding buildings and includes a 732 bicycle rack. ${ }^{20}$,

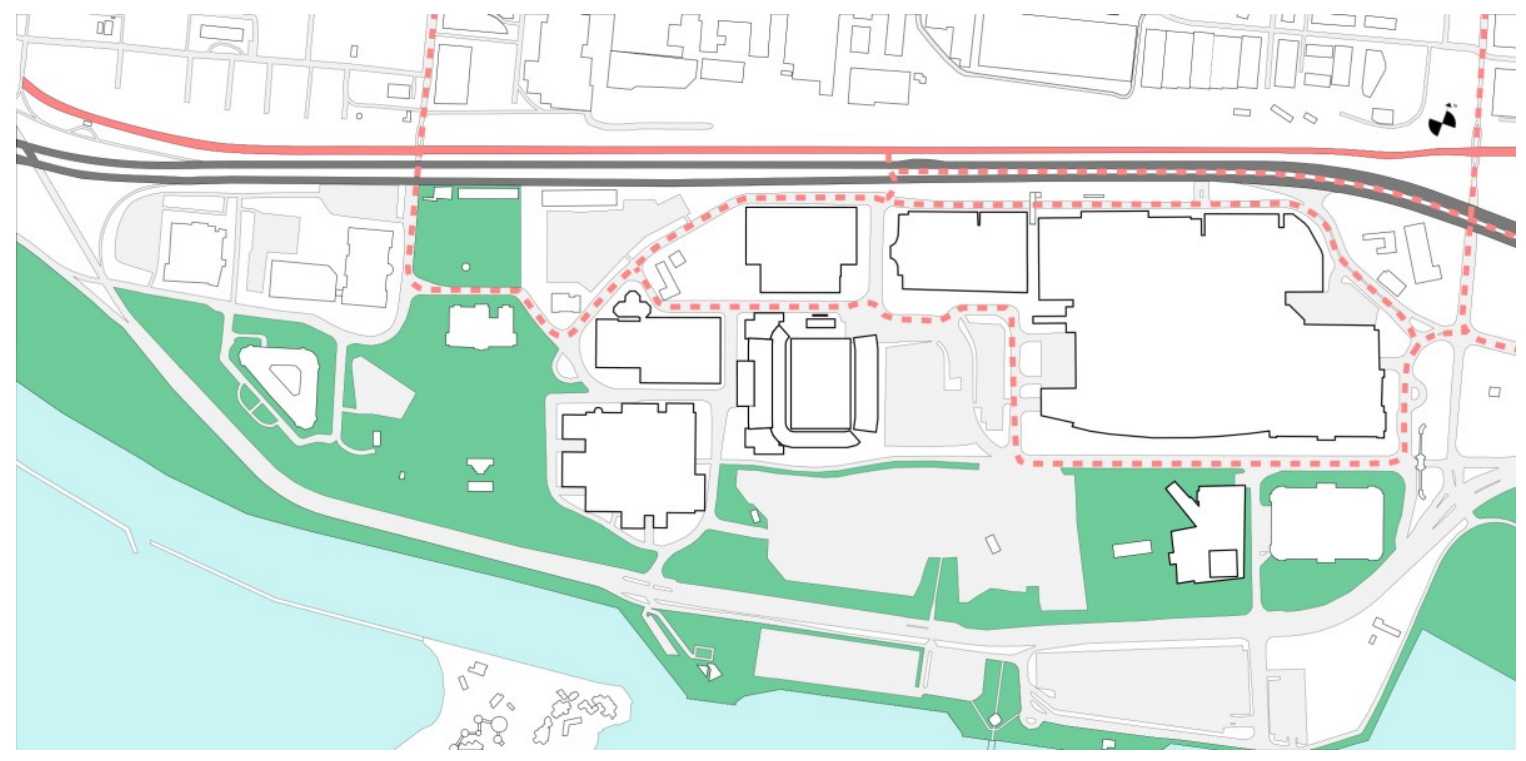

Figure 3-1: Public Transit

20 "Parking at Exhibition Place." Ron Baird | Exhibition Place. Accessed November 03, 2015. https://www.explace.on.ca/visiting/getting-here/parking-at-exhibition-place. 


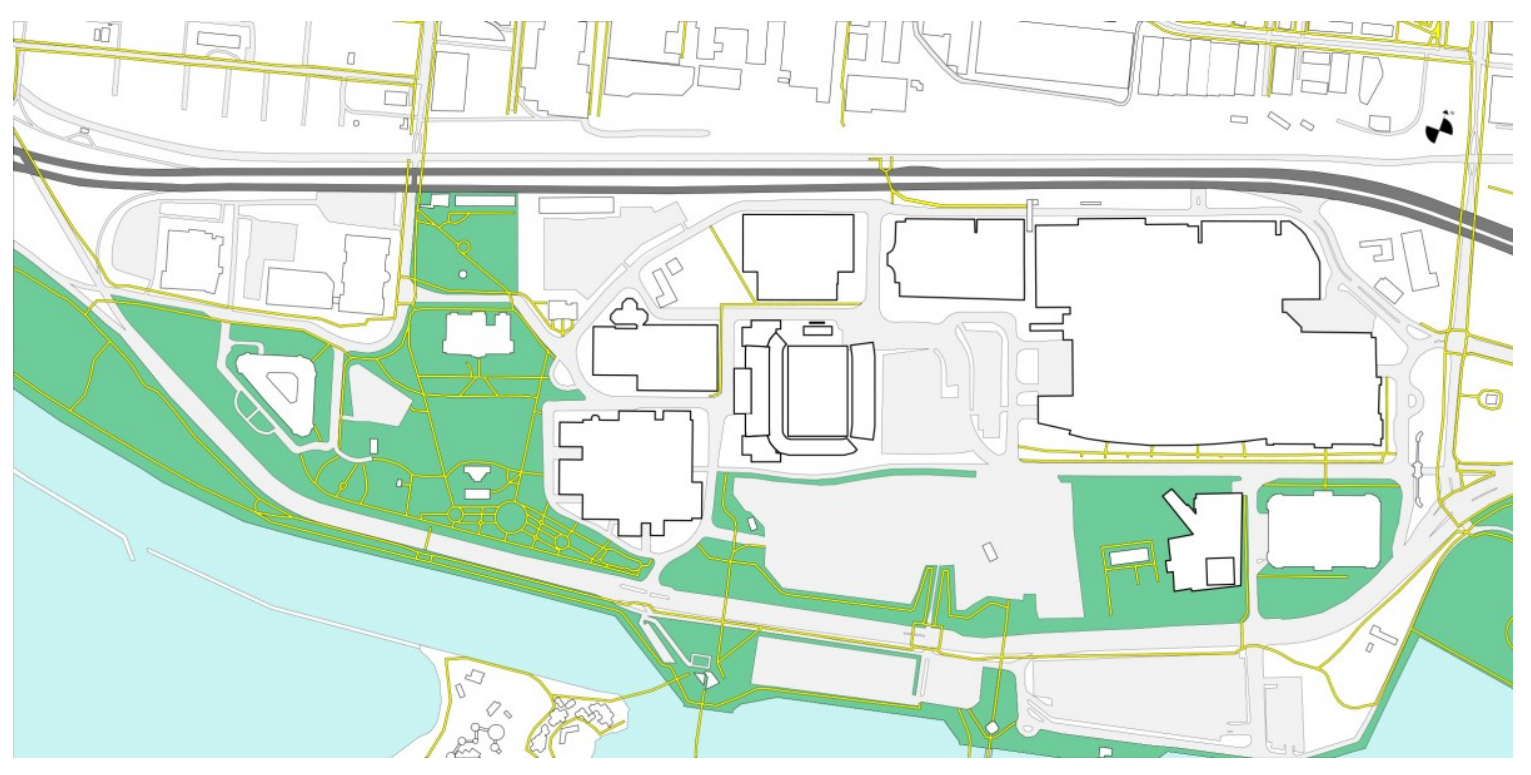

Figure 3-2: Walkway path

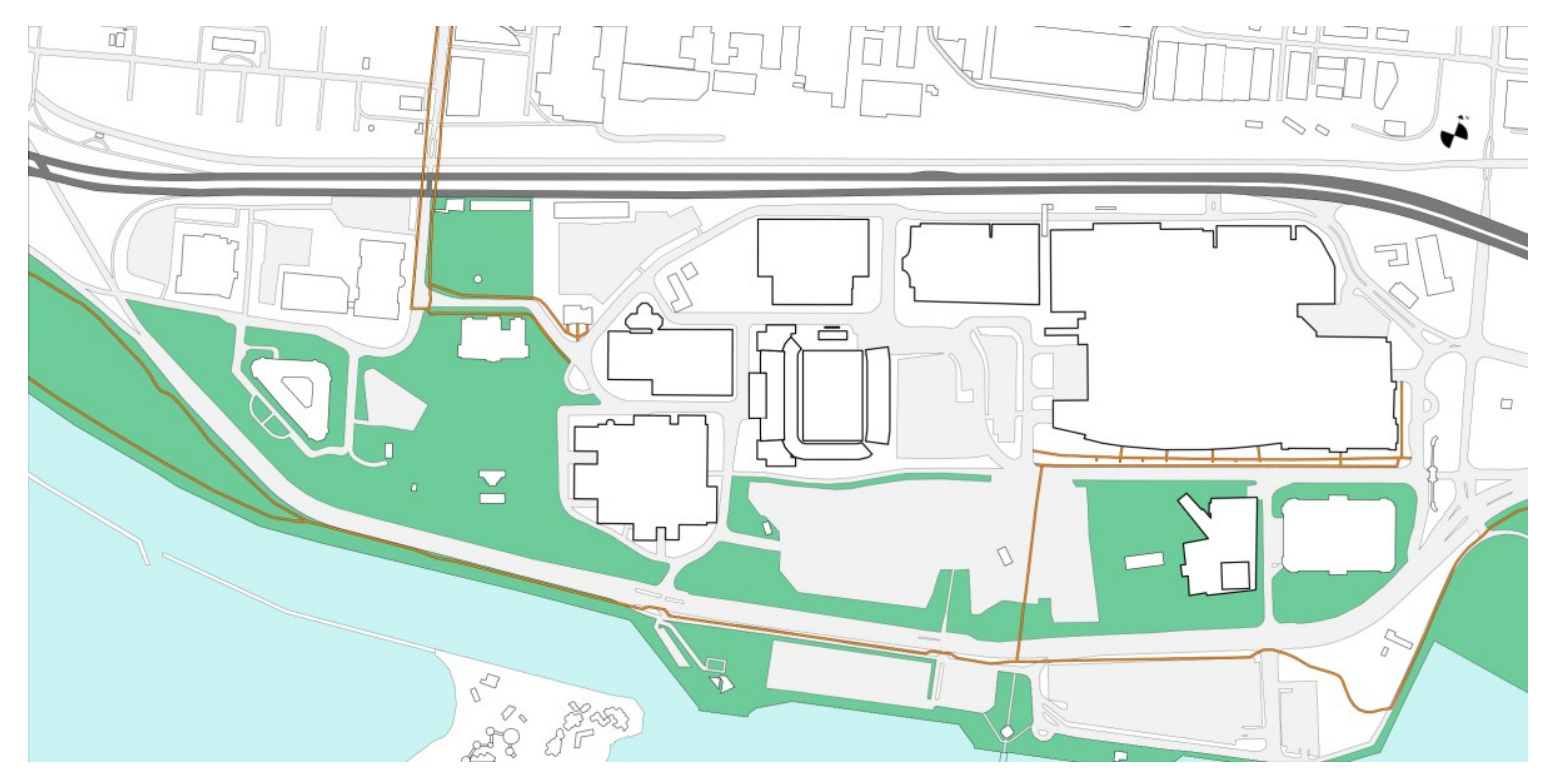

Figure 3-3: Bike Path 


\subsection{Surrounding Context and Buildings}

The site is surround by two sports venues and three exhibition venues.

- BMO Field stadium is the home of the city's Major League Soccer team, Toronto FC, and it is possible to host approximately 31,000 people in the stands. ${ }^{21}$ It was the central venue of the 2007 Under-20 FIFA World cup games (Figure 3-4).

- Coca-Cola Coliseum is home to the city's Minor League Hockey team - the Toronto Marlies and it is possible to host 8,200 people in the facility. It is a historical heritage building that tells the history of Canadian National Exhibition (CNE) from 1921 to the present-day. ${ }^{22}$ (Figure 3-5).

- Queen Elizabeth building, Enercare Centre (Figure 3-6), and Better living Centre: These buildings primary purpose are as exhibition halls. They often serve as venues for major conventions and exhibitions in Toronto. ${ }^{23}$

\footnotetext{
21 "Stadium History." BMO Field. Accessed November 03, 2015. https://bmofield.com/venue-info/stadium-history/.

22 "Coca-Cola Coliseum." Wikipedia. June 07, 2015. Accessed November 03, 2015. https://en.wikipedia.org/wiki/Coca-Cola_Coliseum.

23 "Venues." Ron Baird | Exhibition Place. Accessed November 03, 2015. https://www.explace.on.ca/venues.
} 


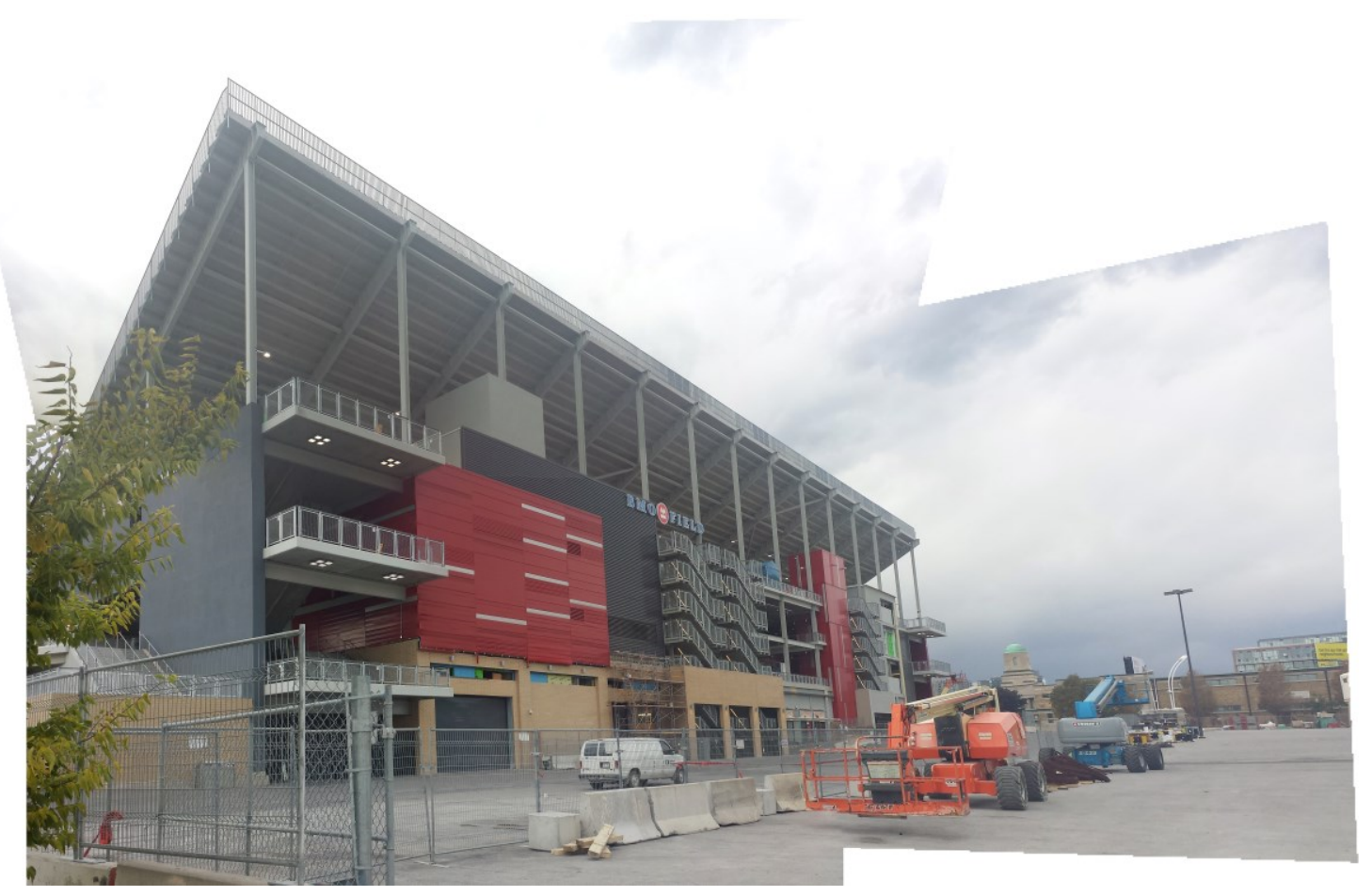

Figure 3-4: BMO Field Stadium

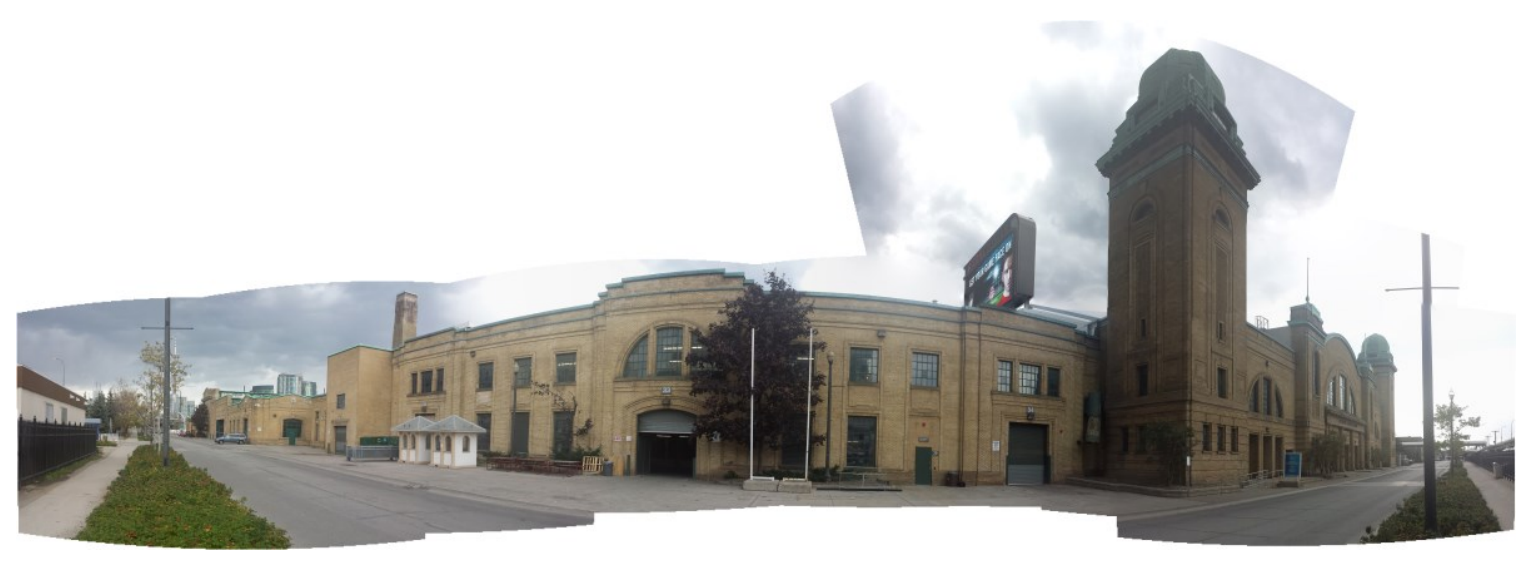

Figure 3-5: Coca-Cola Coliseum 


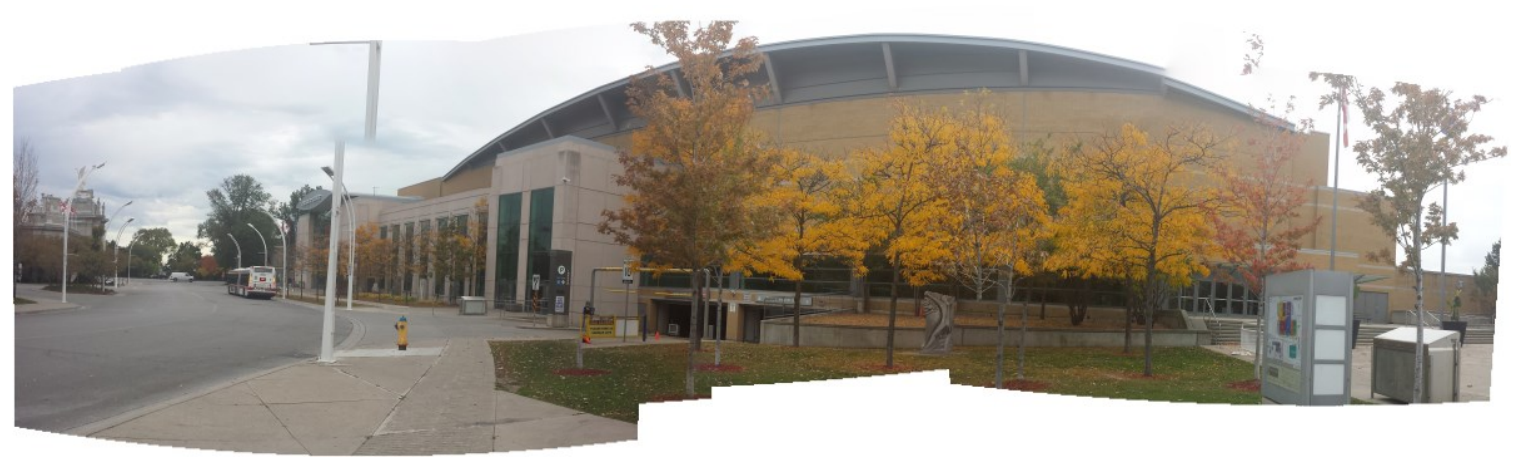

Figure 3-6: Enercare Centre

\subsection{Seasonal Transformations}

The Exhibition place's floating population drastically fluctuate depending on the seasons or sports games. The large site usually sits empty from November to February, even though it is the Minor league hockey season. Parking spaces are used for few hours at best. The site remains mostly empty over these four months. When the Major League Soccer season begins in March, there is a little more activity on the site. In May, the site population reaches a peak when the Ontario Place water amenity park is open. The site is used by Exhibition Place visitors and Ontario Place's sub-parking spaces. Exhibition place is largely used as a parking space all year around. However, the site is barely used for other cultural experiences or events (Figure 3-7, Figure 3-8).

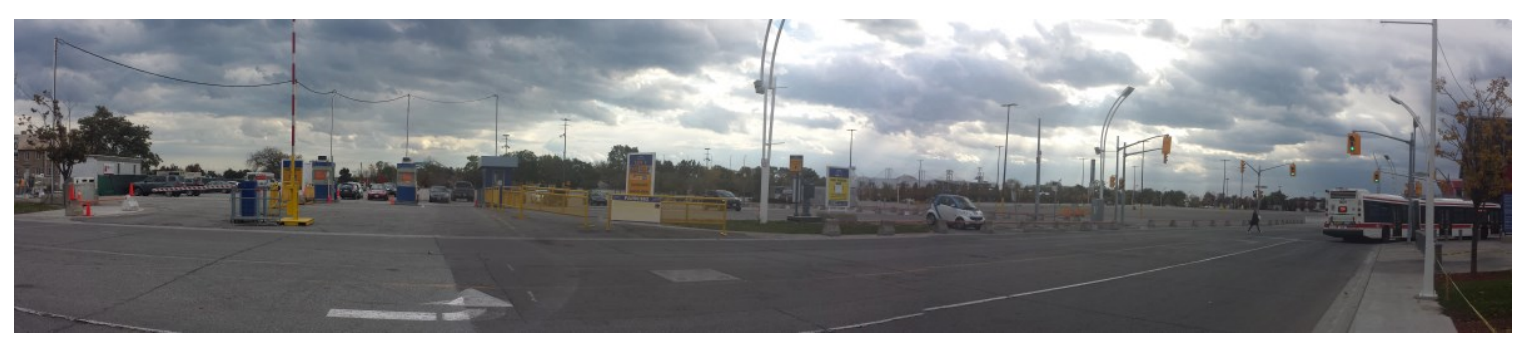

Figure 3-7: The Site in fall period 


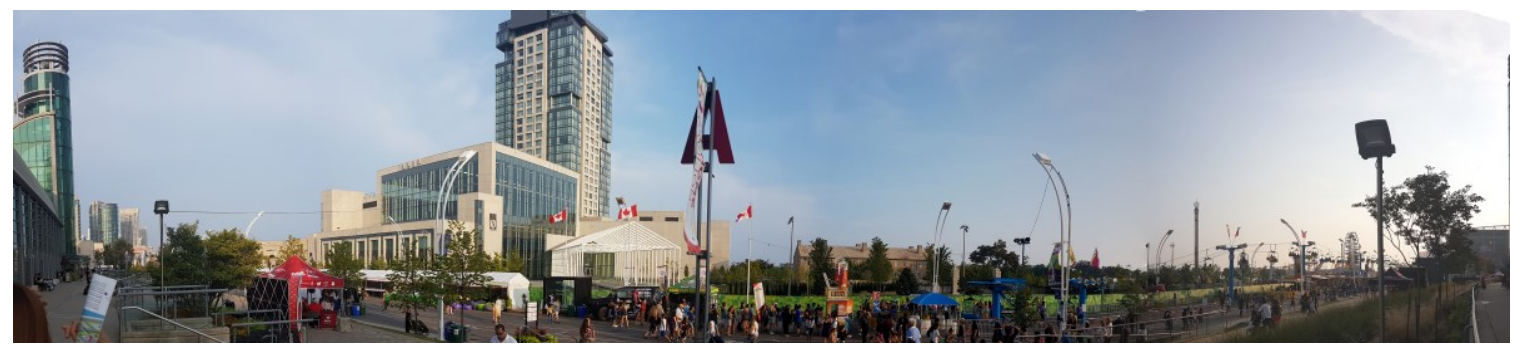

Figure 3-8: The Site in summer period

\subsection{Planning (Building / Program)}

During the last two decades, there have been consistent and continuous discussions regarding the future of Exhibition place. These discussions have revolved around its potential use and a "re-invention" of its spaces. A key challenge for the public realm was to understand how public spaces should be designed, so that they be useful and an enjoyable for the many diverse inhabitants of Toronto. Modern public spaces cannot be restricted to highly specialized purposes or programs, in part because the lifestyles of citizens are not the same as they were yesterday. ${ }^{24}$ It is of course, important to have particular programs and functions, however, it is increasingly difficult to have single function spaces. Moreover, the architecture of the public realm cannot ignore rapidly changing inhabitants' lifestyles. Therefore, new public facilities should be designed to be flexible and adaptable for varying demands. Simply, modern public facilities should be comfortable, attractive and accessible for activity.

In the 2015 Pan Am Games, 29 sports competition venues across 14 municipalities were used for the competition. 10 venues were purposely built for the games. The use of

\footnotetext{
${ }^{24}$ Lee, Uje. Minor Works: Urban How: Virtuous Urban Pieces: Civic Engagement. Series 347. Seoul: C3 Publishing, 2013. 43
} 
existing venues resulted in increasing travel times between sites. The farthest site used during the Pan Am Games was approximately $203 \mathrm{~km}$ from Exhibition Place. It is challenging to consider distributed planning because disparate sites are difficult to accommodate and are generally less popular with viewers because of added travel times. The purpose of this sports complex includes the following:

- To introduce new and unfamiliar sports to city life and experience.

- To build support and community engagement for these activities.

- To create a central sports community in Toronto in order to add to a higher quality of life in the city.

- Exhibition Place is large enough for a varied sports complexes and it includes five venues. These are based on sports that require particular environments or certain distances from the city (Figure 3-9, Figure 3-10). 


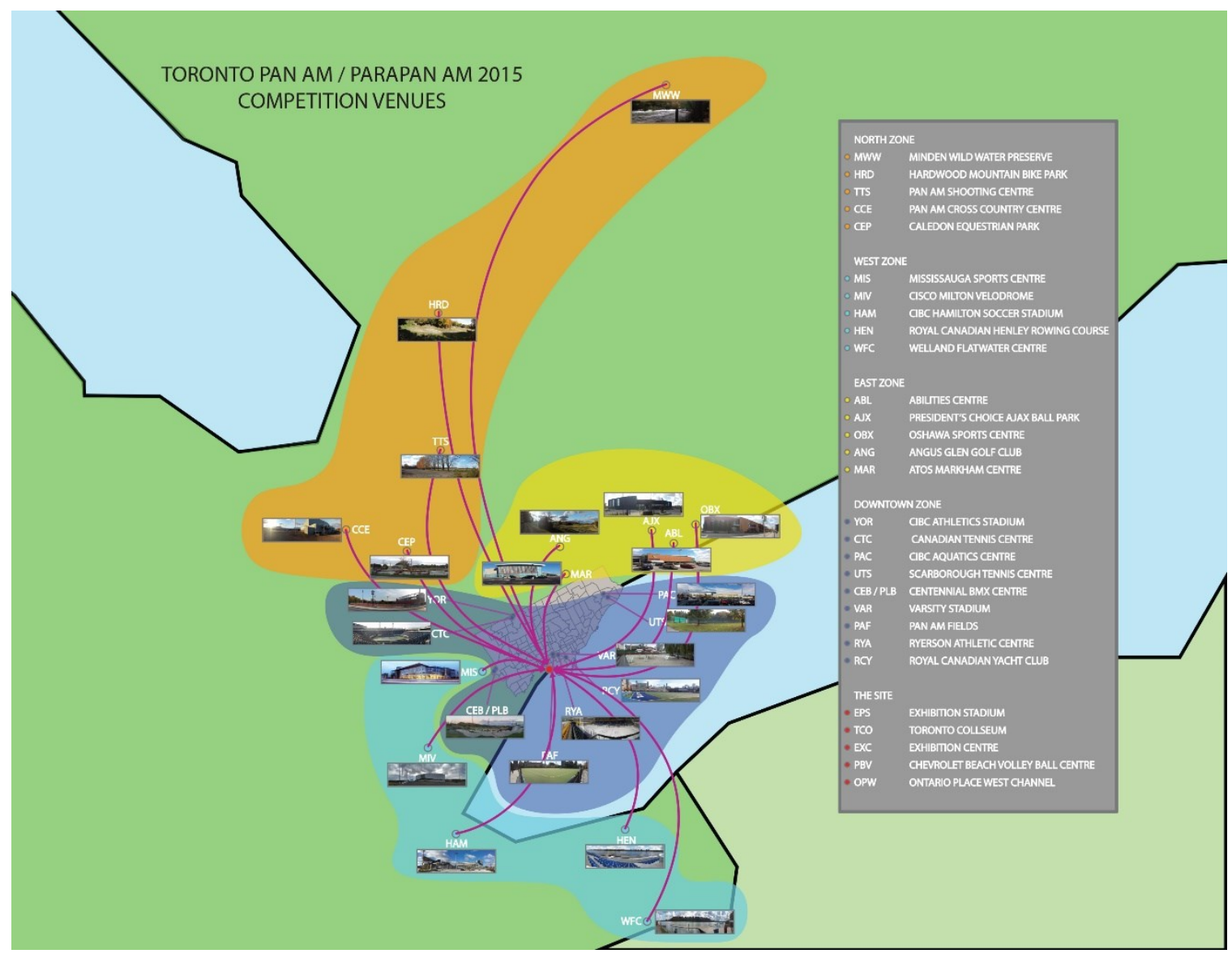

Figure 3-9: 2015 Pan Am Game venues to proposed idea

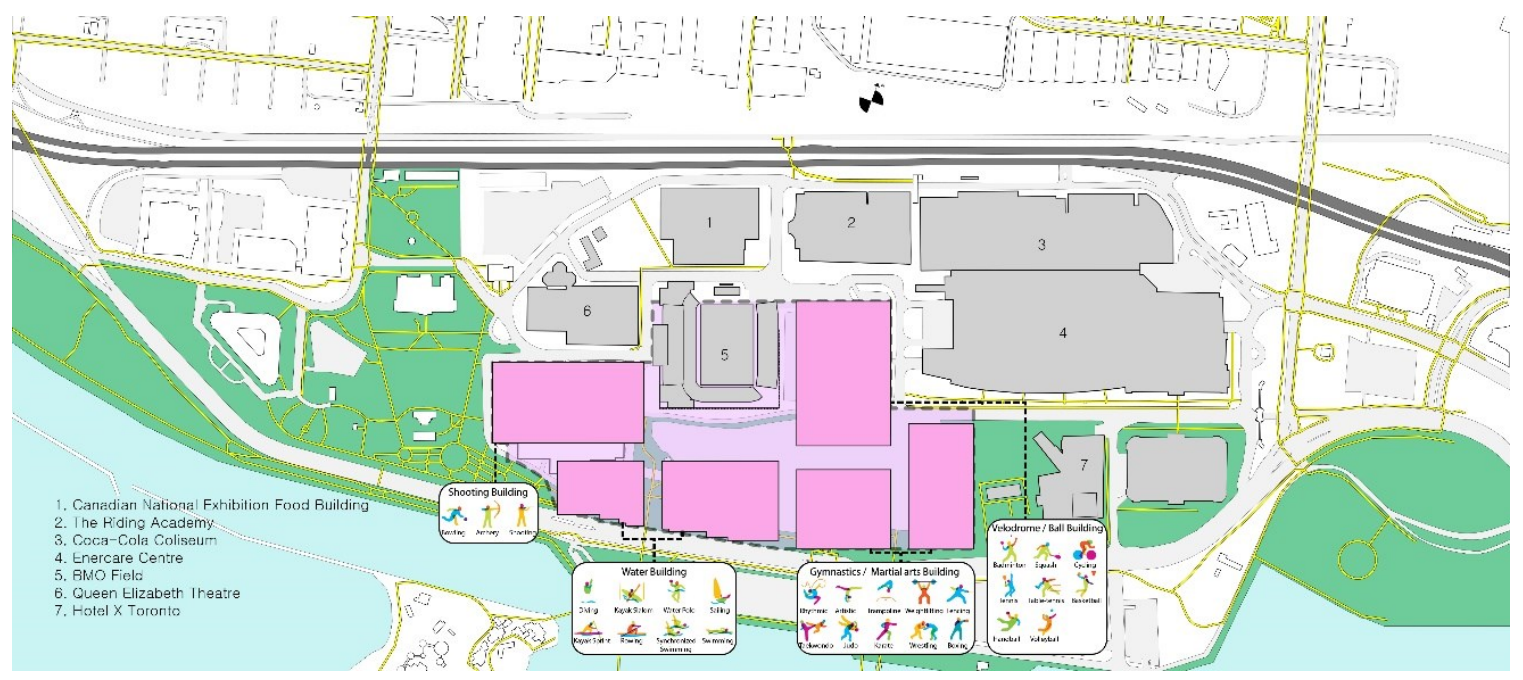

Figure 3-10: Proposed project in the site 
Services Building. This building is located underneath the BMO field stadium at Exhibition place. The site has 6,450 parking spaces including both on-ground and belowground (1,300 spaces) lots. Developing parking spaces as part of an urban sports complex means ground parking space should be part of the overall sports complex planning. Parking should not be entirely removed, because the project is about increasing building density at the site. Parking is an important part of the site - and project - considerations.

Shooting building. This building has three specific programs; archery, shooting and bowling. All require specialized equipment, training and event spaces.

Gymnastics Building. This building contains spaces related to martial arts and gymnastics based sporting programs.

Water Building. This venue contains program, spaces and activities that are related to swimming and water-based sports - including canoeing, rowing and sailing. The building also serves as the start and finish line for water-based competitions, and is located on and connected to the open waters of Lake Ontario.

Velodrome / Court Sports: This is the project focus for the thesis design. And is the developed building of the sports complex and this proposal. The building contains a number of different programs that include cycling, badminton, tennis, handball, volley ball, and basketball facilities. The Velodrome engages with the diverse and vibrant energy of uniquely different facilities throughout the building. Since, new parking spaces are required; 435 new parking spaces with 33 disable parking spaces and 230 bicycle racks have been provided as part of the thesis design (Figure 3-11). 


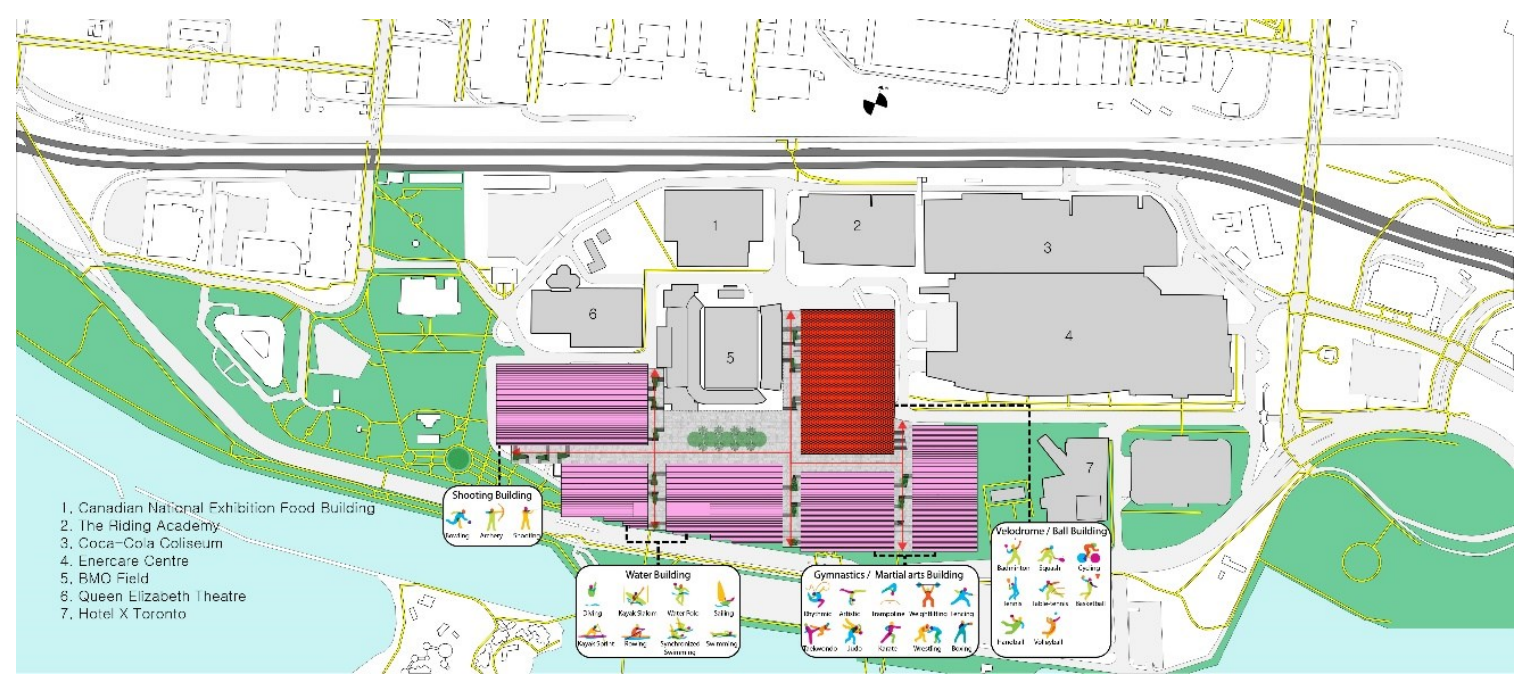

Figure 3-11: Proposed project with new circulation through the site

\subsection{Design / Structure}

The design of the new sports complex is conceptually related to the idea of flowing water with a beehive roof pattern. Conceptually, Lake Ontario's fresh water and tides flow over from the lakeshore to the site and informs some of the formal expressons of the structure. To asssit with this, the design has a reduced profile of water and tide shaped roof slope, so as not to interupt the exisiting buildings and the site skyline. Three levels of the building are below-ground - out of a total of seven levels, and as a result, the massing provides less of a visual impact on the site. Newly developed circulation circulate through the sports complex to help to set new boundaries and threshholds (Figure 3-12). 


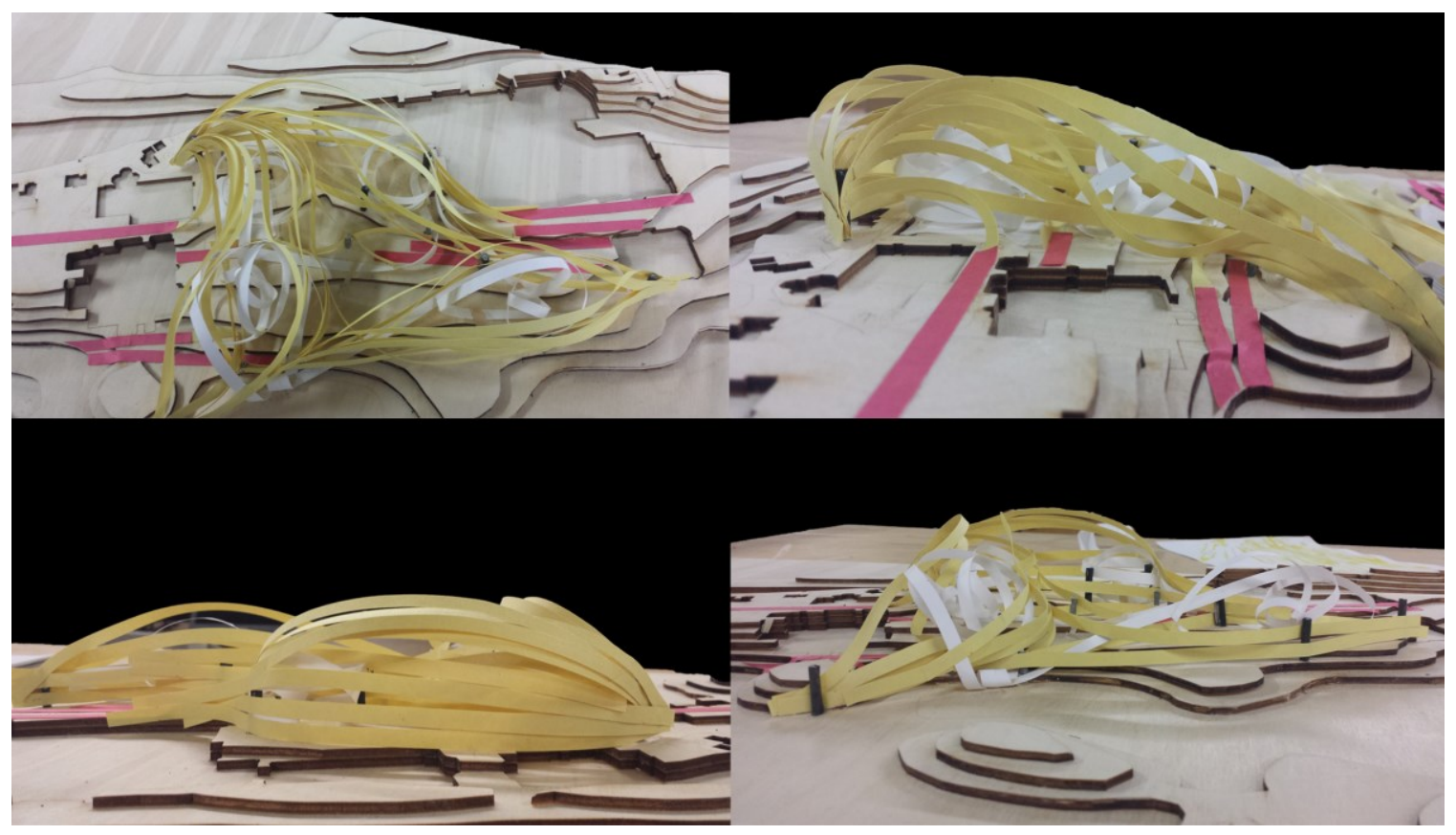

Figure 3-12: Flowing water concept

\subsection{Materials}

Wood is one of the oldest natural architectural materials and has long been recognised for its structural and decorative properties and potential, making it an adaptable material for architectural purposes. The transformation of innovative wood structures has helped shape modern architecture and has helped us to re-imagine the future of wood construction. ${ }^{25}$ Most of the construction industry still uses cement-based and clay materials. However, what should be noted here is that since the 2005 Kyoto Protocol agreement ${ }^{26}$, wood has been adopted as the most eco-compatible construction material in regards to sustainable architectural design. In terms of its strength, absorbency, biodegradability and

\footnotetext{
${ }^{25}$ Lee, Uje. Cultural Facility Three Approaches: Wood and Architecture. Series 344. Seoul: C3, 2013. 38 26 "Kyoto Protocol - Targets for the First Commitment Period." UNFCCC. Accessed June 15, 2016. https://unfecc.int/process/the-kyoto-protocol.
} 
recyclability; no other material has comparable properties. Wood is increasingly more widely recognized as a highly innovative matieral and has become a culturally common building material. This proposal aims to use wood and to demsontrate how it, as a material, might offer a new bridge between tradition and the future (Figure 3-13, Figure 3-14).

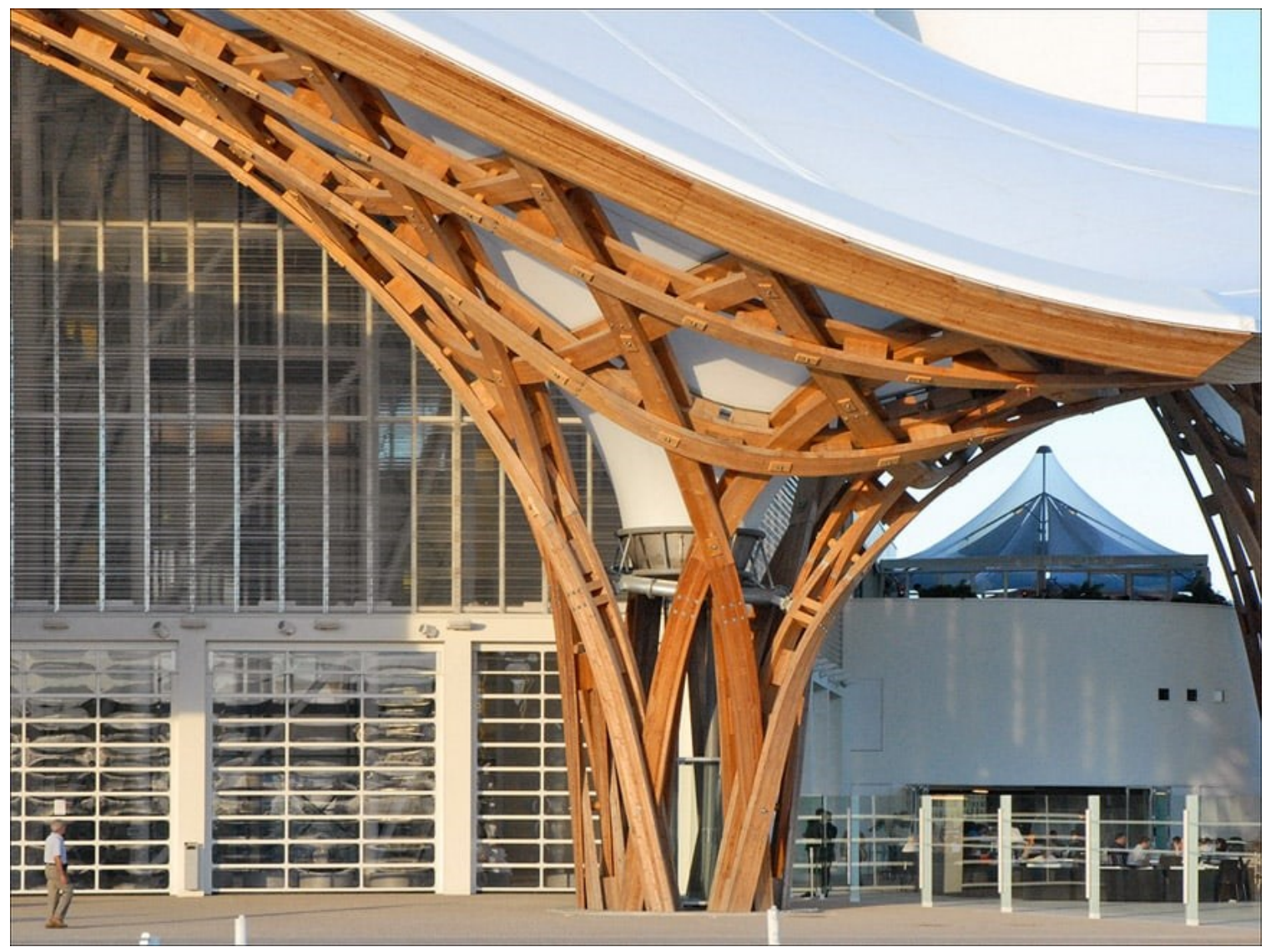

Figure 3-13: Precedent-Centre Pompidou, Metz 


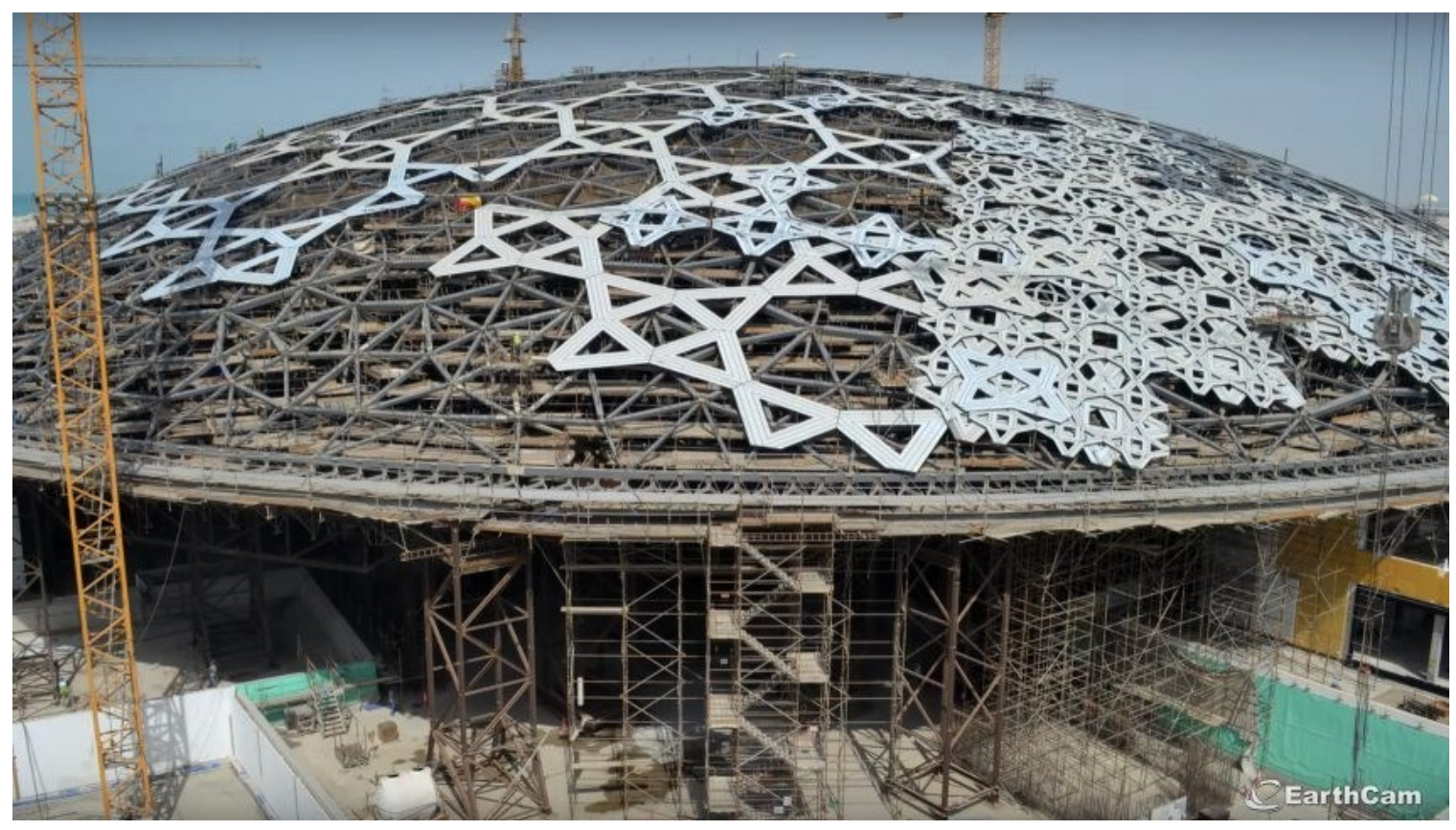

Figure 3-14: Precedent- Louvre, Abu-Dhabi

The roof and structure of the proposed building is tied directly to Canada's connection to timber. Unlike many of the standard stadiums around the world, this proposal centers on the use of timber and wood. Motivated in part by the importance of Canada's lumber industries, the project also acknowledges recent challenges with Emerald Ash Borer (EAB). Since 2003, the Ash tree population in Canada has been devastated by the EAB. Millions of the ash tree species have been cut down - a process that continues today. According to the Government of Canada, as well as industry experts and material engineers, the EAB does not lessen the structural capacity of the wood, and they can still be used in structural applications for buildings. ${ }^{27}$ In fact, using these felled trees is a potential cost and

\footnotetext{
27 "Emerald Ash Borer." Natural Resources Canada. July 31, 2016. Accessed May 05, 2016. https://www.nrcan.gc.ca/forests/fire-insects-disturbances/top-insects/13377.
} 
expense saving strategy, while also serving to symbolically recognize Canada's natural image and resources.

\subsection{Roof}

This project approaches the design of a public cultural facility with a focus on the roof. The difference between the main space and the auxiliary space is evident in many aspects, such as function and flow. These differences, however, are unified into a definite geometric domain created by the roof. With the roof, the flow of space can be gathered in one place - naturally spreading - and also forms a relationship with the outside. The roof allows inhabitants to blend into a space freely through various activities. In this sense, the roof becomes the merging element among the various spaces, performing the responsibility of concentrating the functions while still being able to then disperse them into their surroundings.

The proposal needs to be considerate - as any sports venue does - of sightlines, particularly for large events. In order to assist in the design process, a decision was made to employ a long-span structural system in order to better asisst and provide uninterrupted views while attendng and watching events. Long span structures are commonly employed in sporting venues today. They are usually constructed in combinations of metal trusses and columns, as well as cables, concrete footings, and support structures.

The sports complex design will use inspiration from the beehive's hexagonal pattern and will use a Glulam structure for the materiality of the roof. The structure aims to create a grand elegance with natural material, and will divide in certain patterns in order to give more flexability. Moreover, this pattern is the most durable and efficient structure 
found in nature. The Glulam pillar is surrounded by metal pipe columns that supports a roof structure that reaches six stories in height. The light wooden roof significantly reduces the load at the joints of the Glulam columns. Lighting and ventilation are two important sustainable and ecological design points in this building as well.

This project proposes a larger and more focused use of the material - simple but elegant Glulam pillar columns as supports, and arched Glulam frames in order to support a big roof required for the ceiling. Glulam manufacturers and standards sizes can vary, however typical ratios of depth, width and length are often very similar. Glulam can, of course, also be custom designed depending on the nature of the building (and its budget).

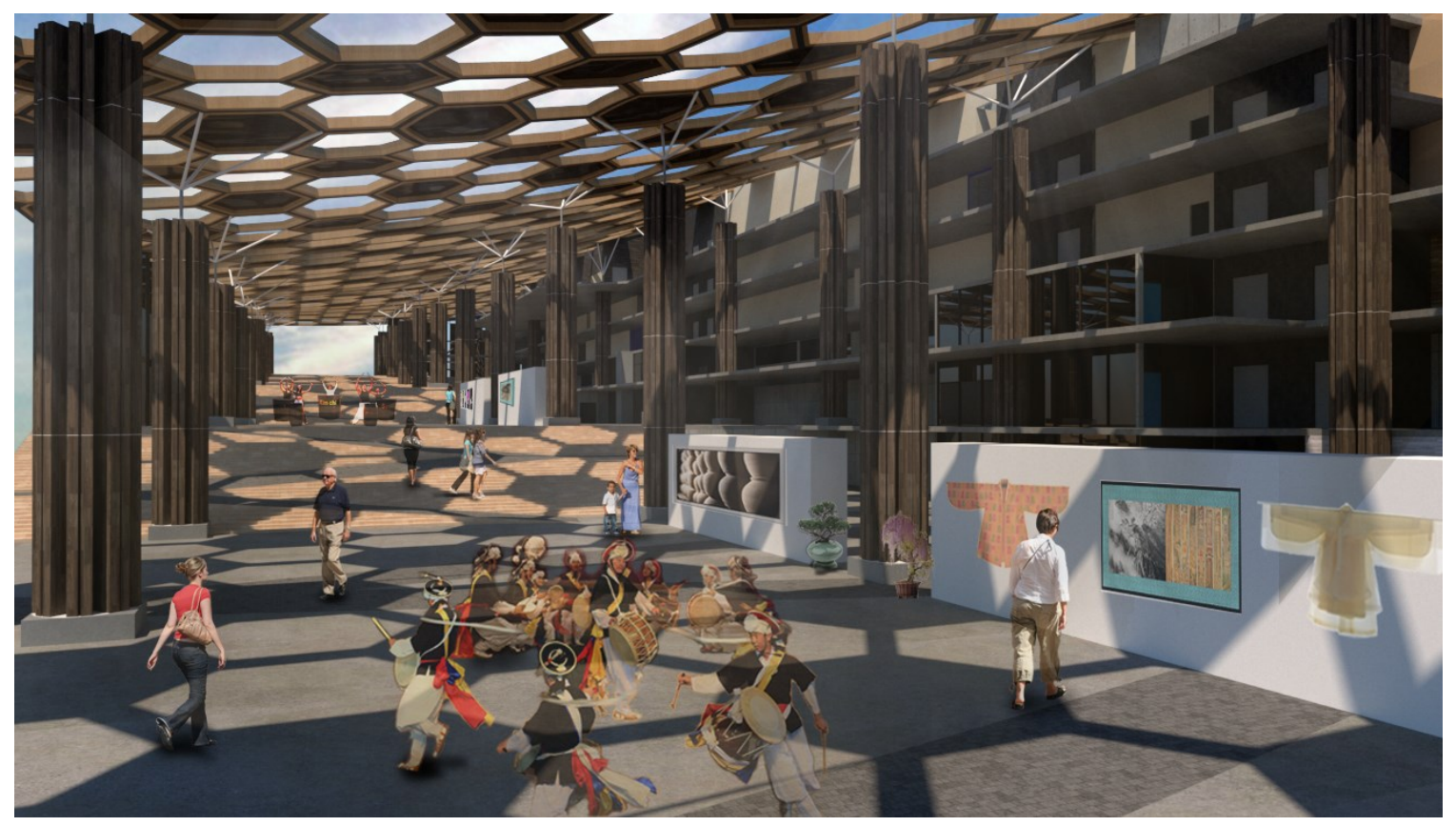

Figure 3-15: Exhibition hall 1 


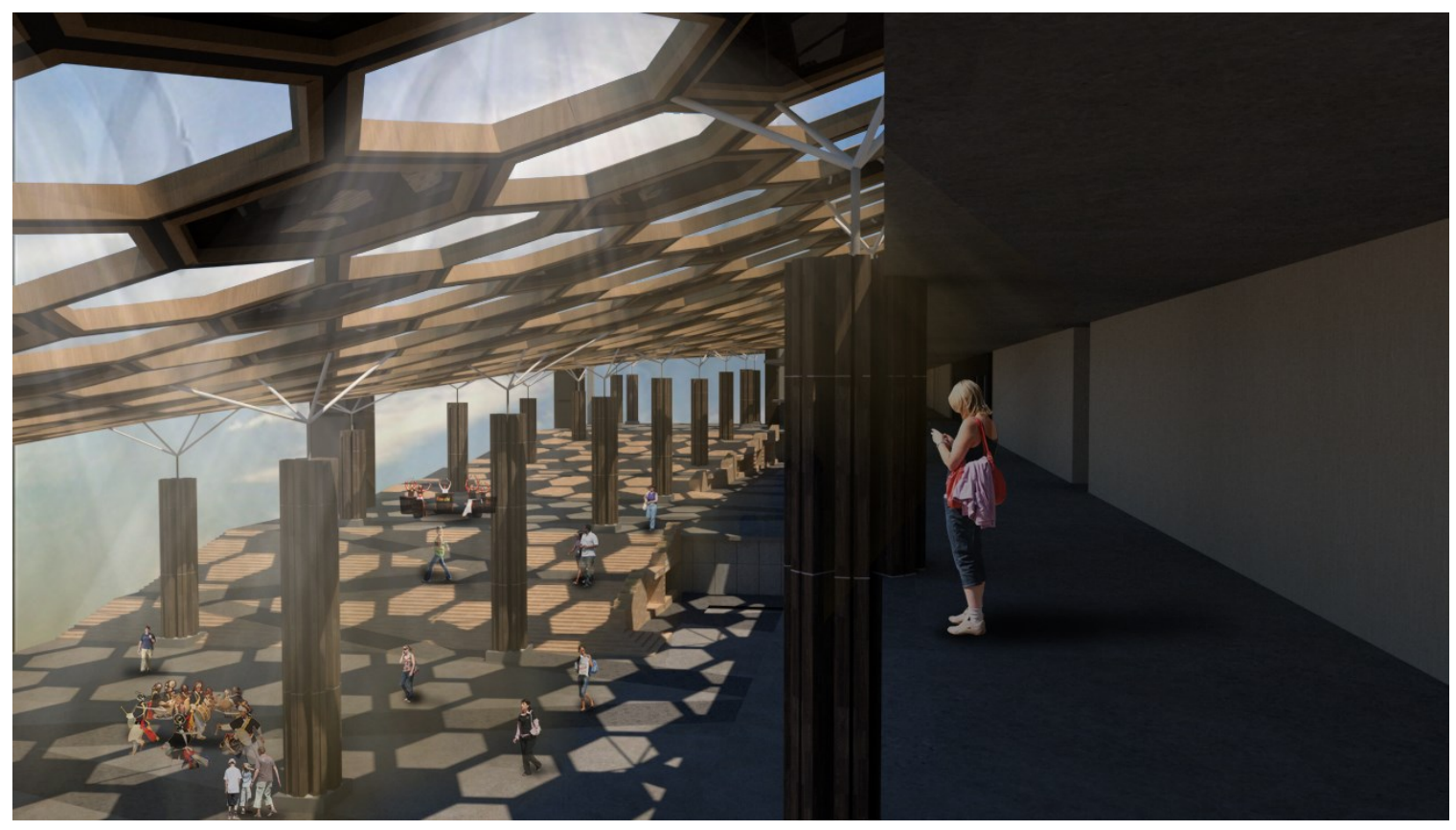

Figure 3-16: Exhibition Hall 2

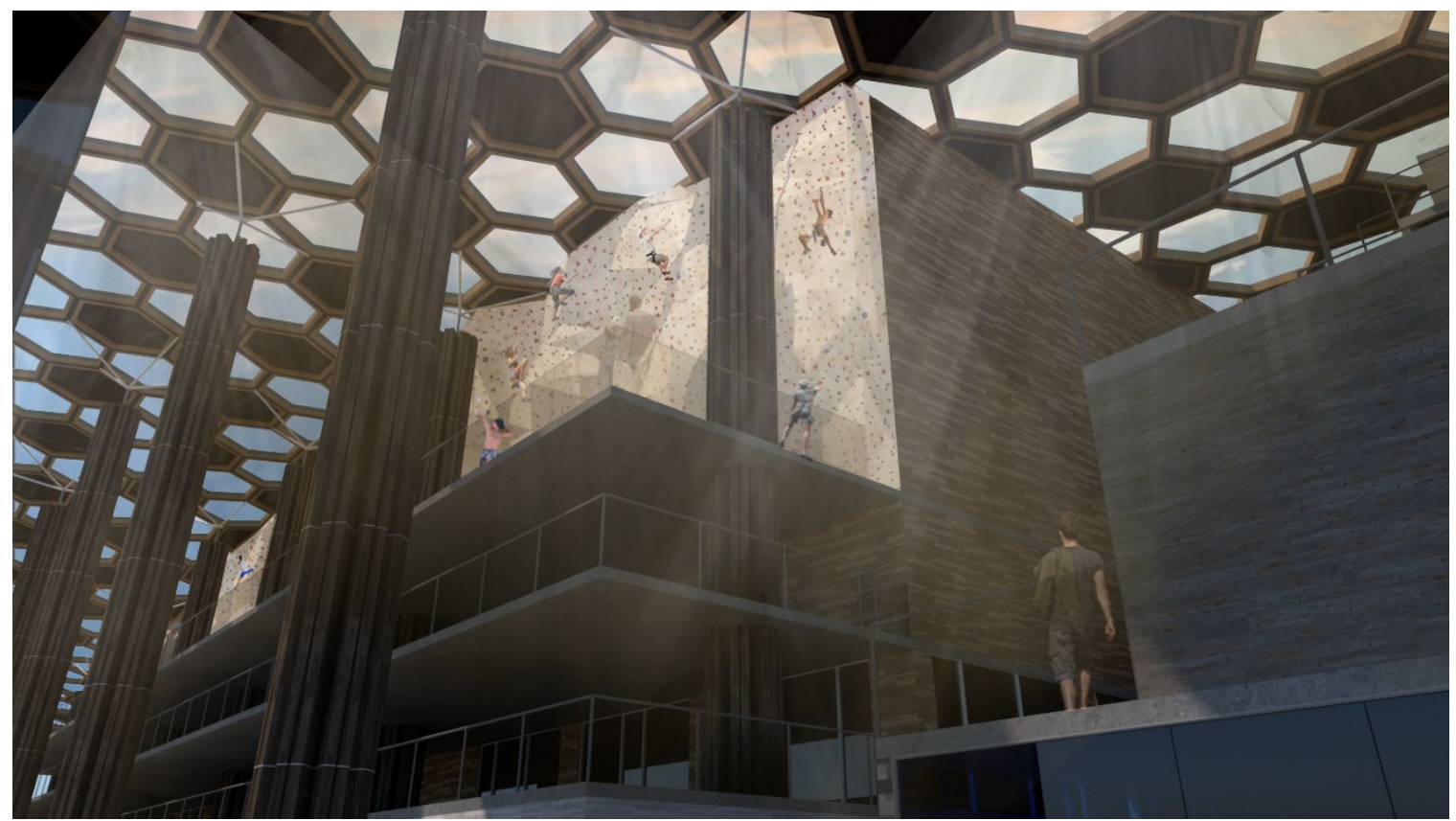

Figure 3-17: Rock Climbing facility 


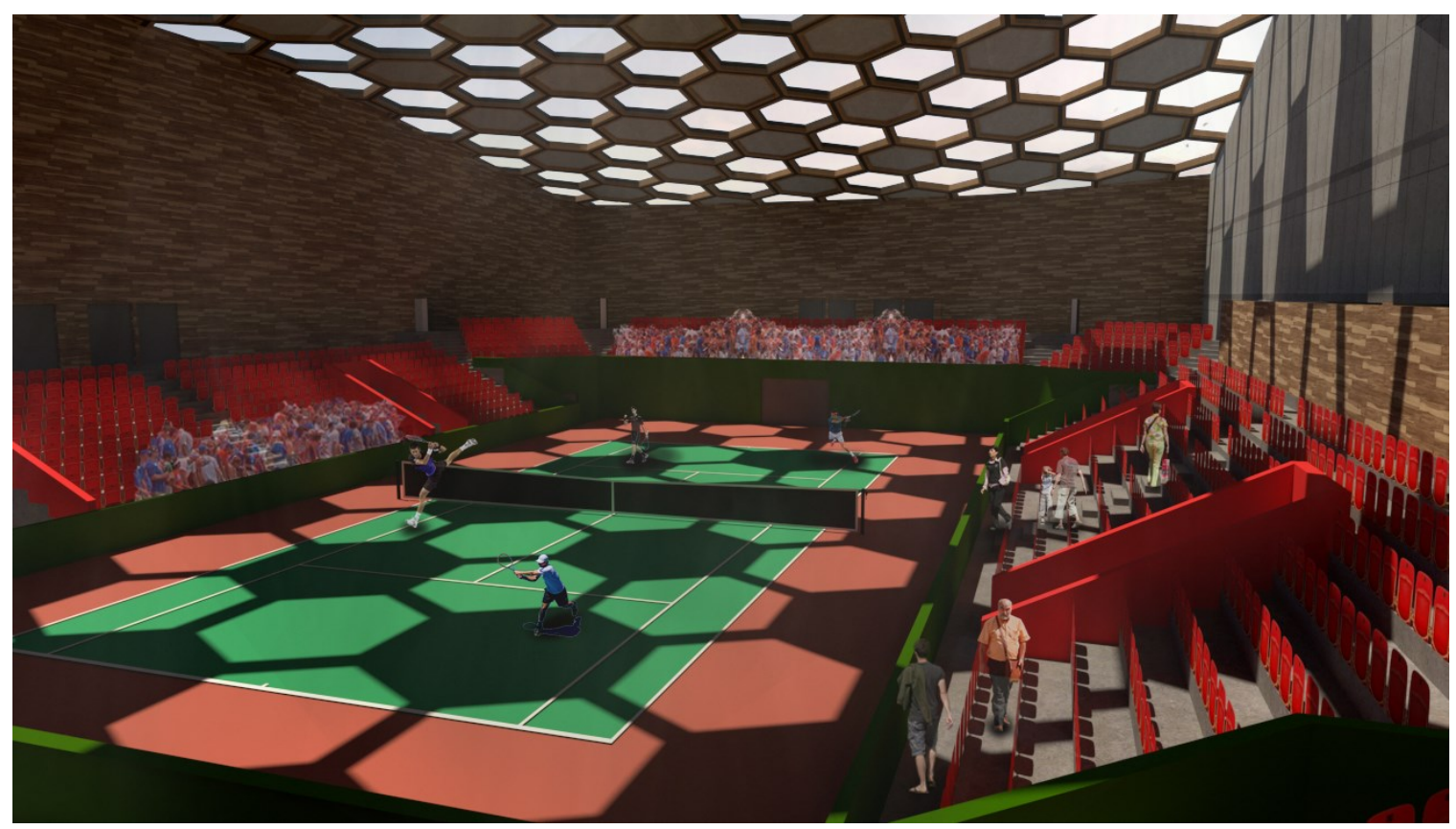

Figure 3-18: Tennis court

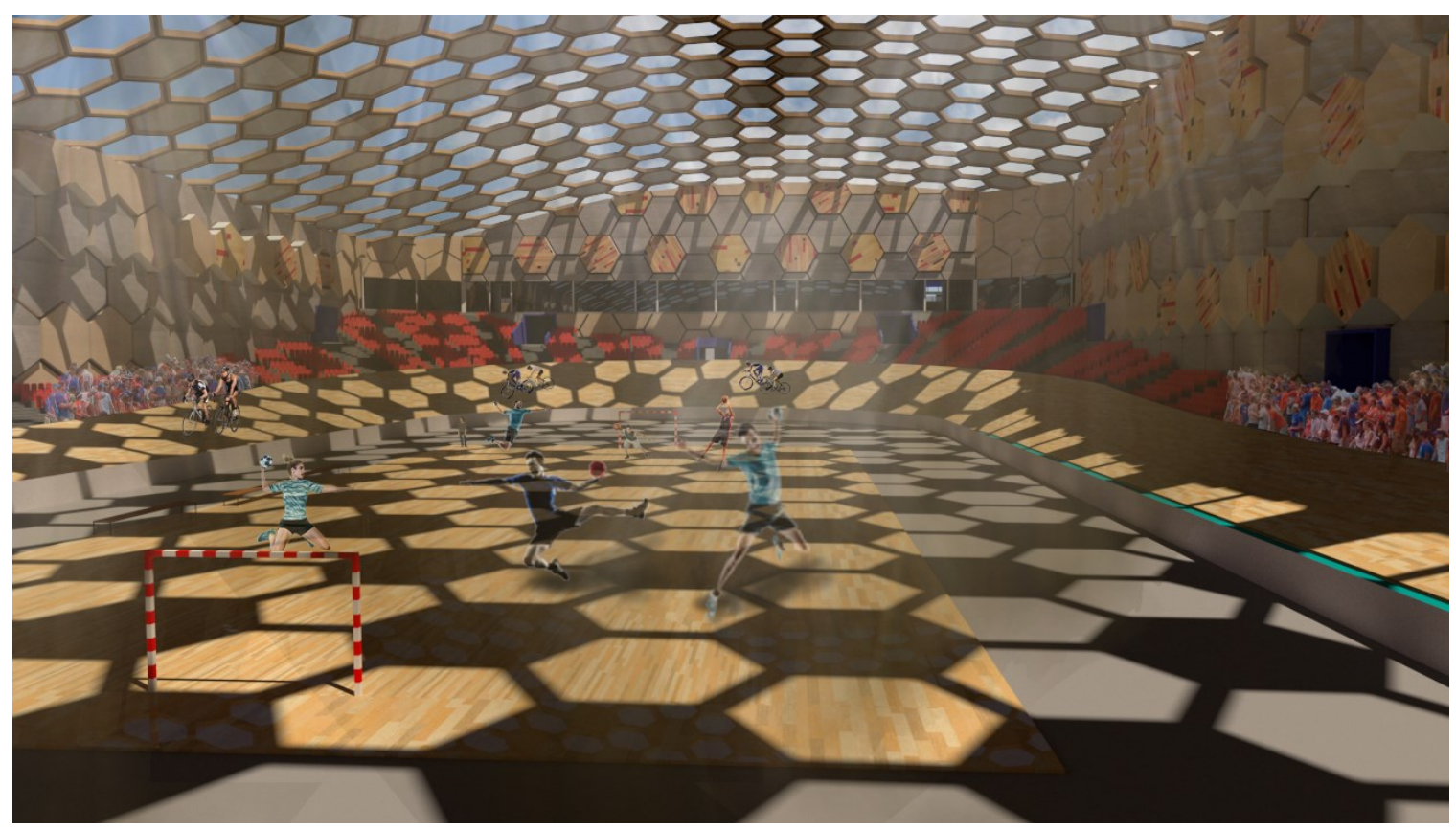

Figure 3-19: Velodrome / Handball court 1 


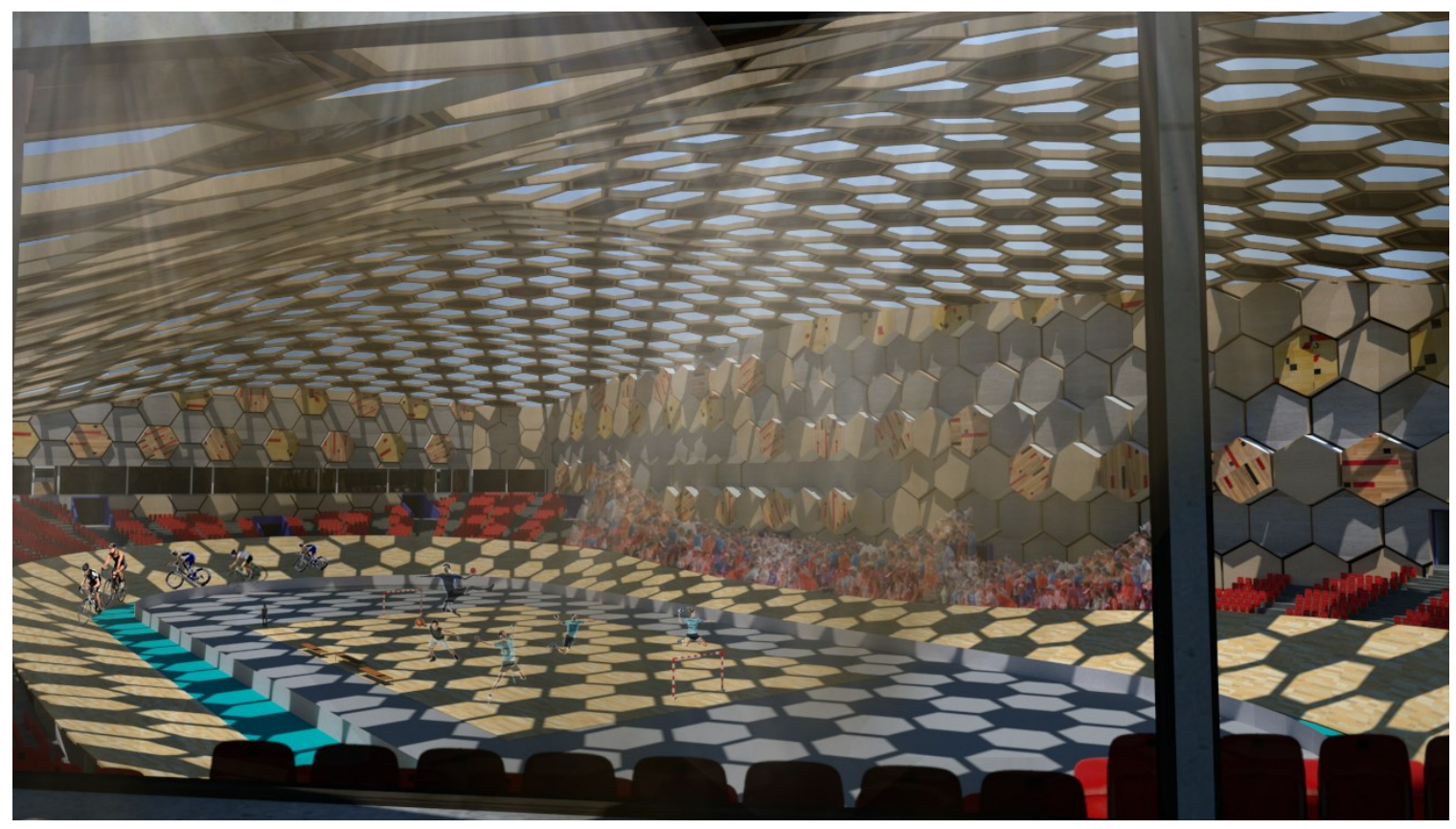

Figure 3-20: Velodrome / Handball court 2

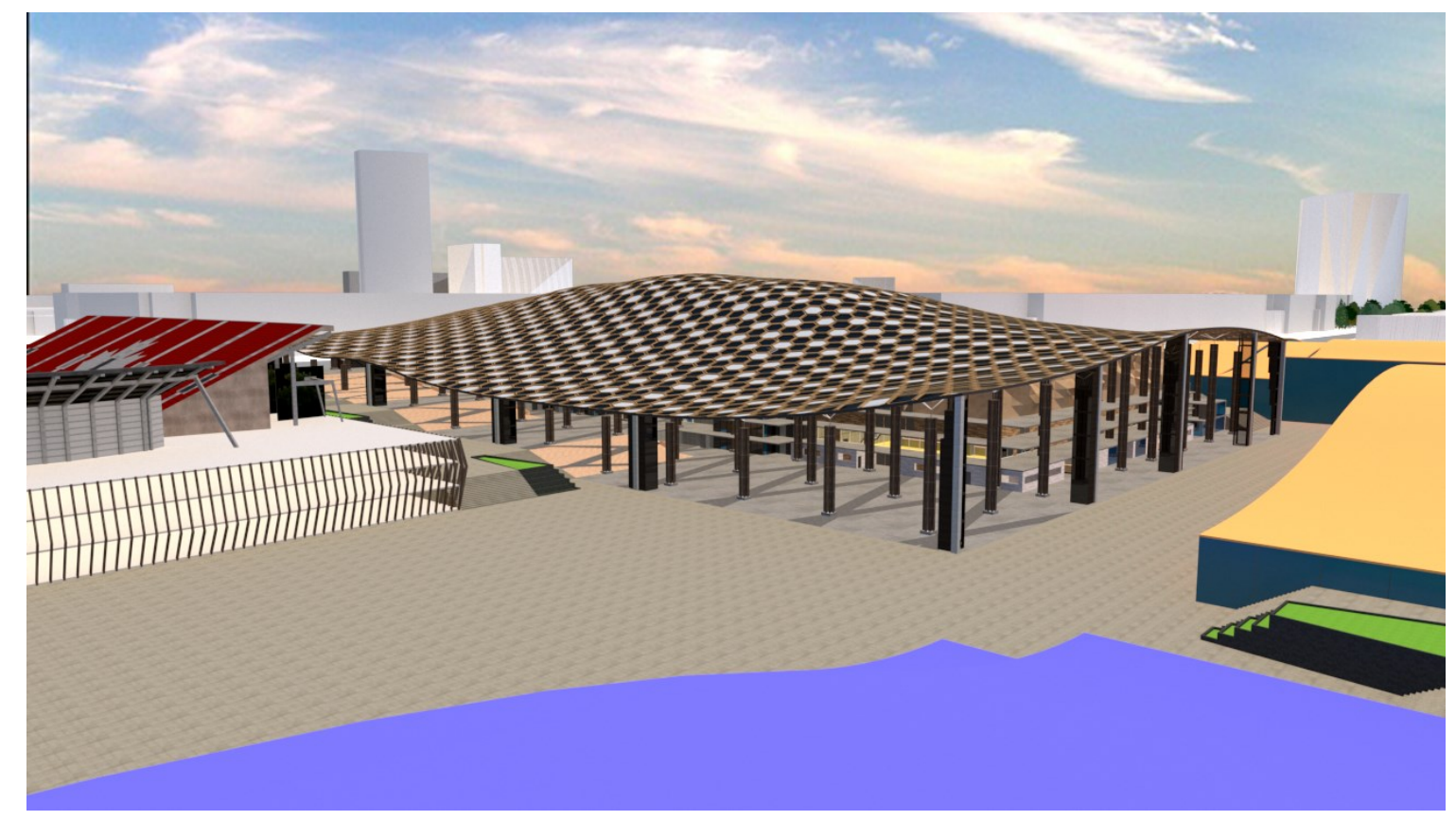

Figure 3-21: New circulation corridor to the project 1 


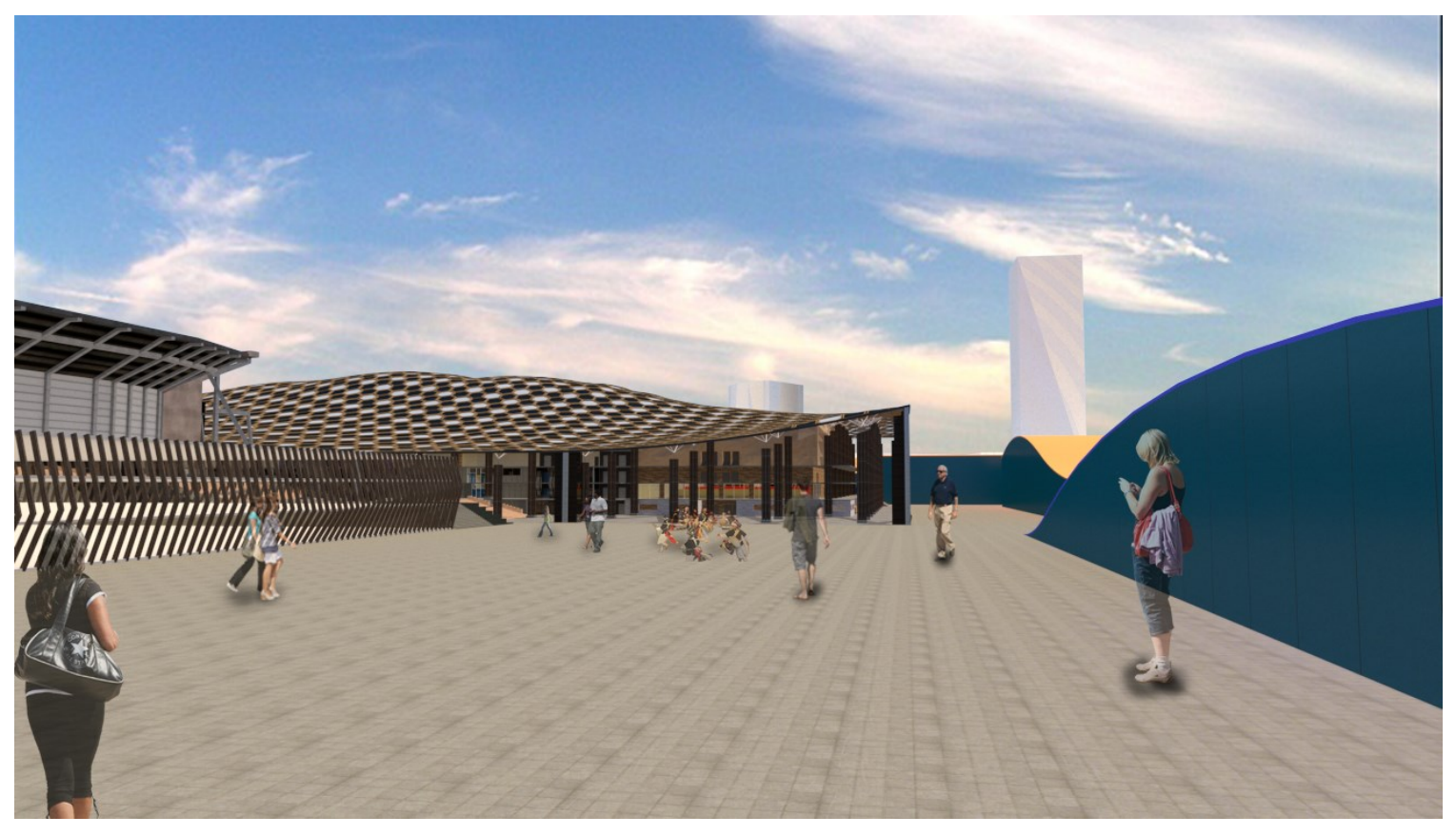

Figure 3-22: New circulation corridor to the project 2

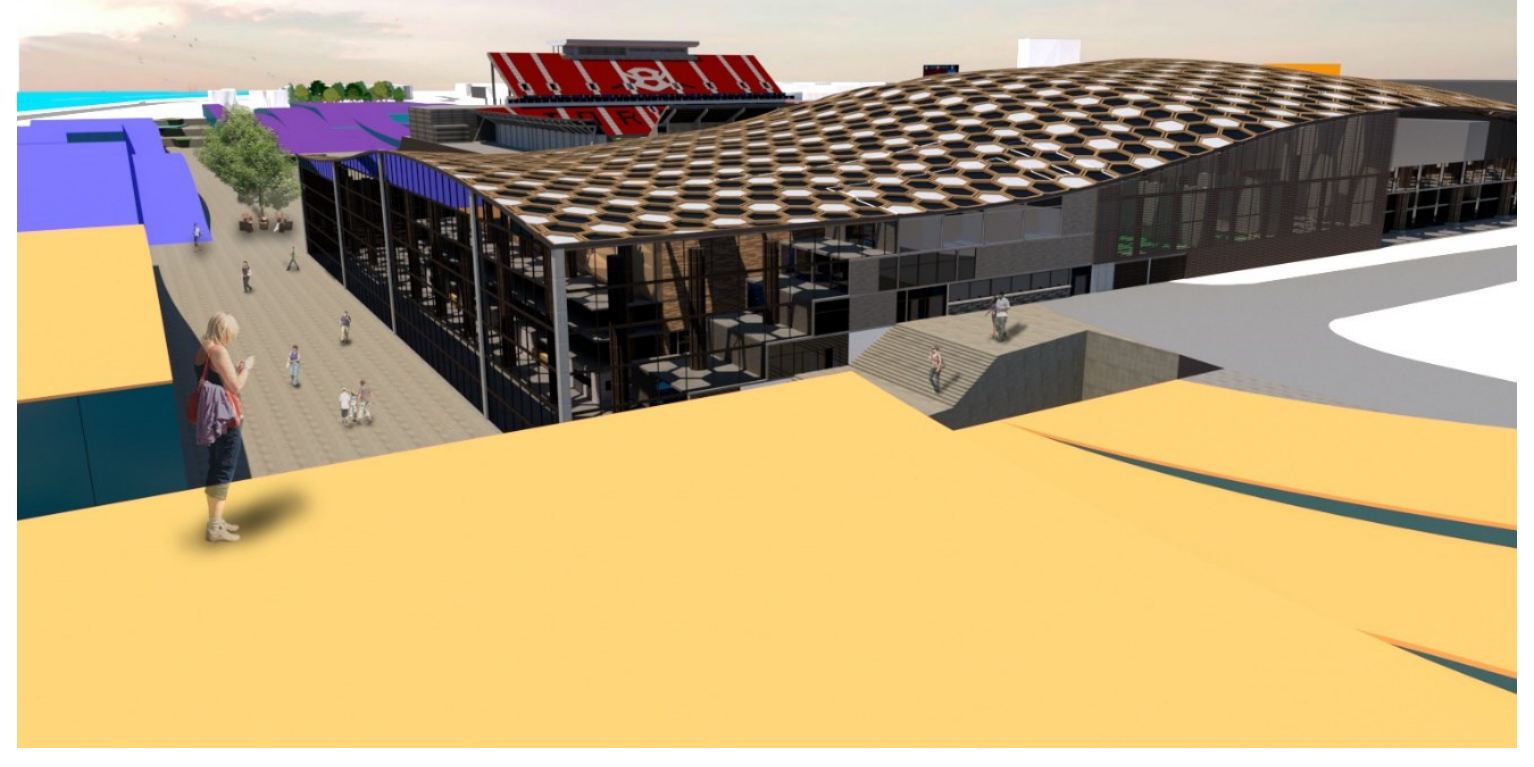

Figure 3-23: New circulation corridor to the project 3 


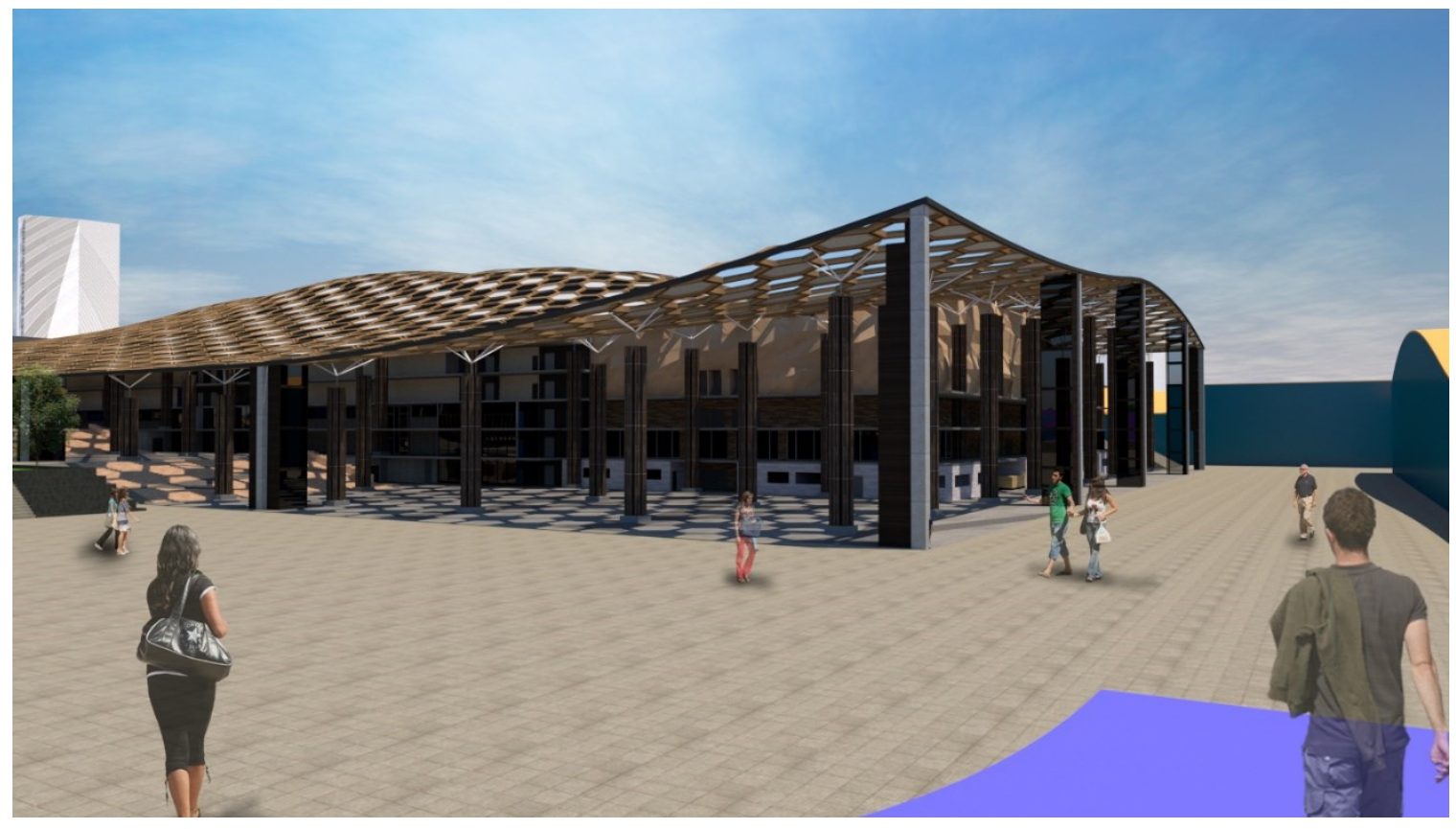

Figure 3-24: Opened folding glazing winter view

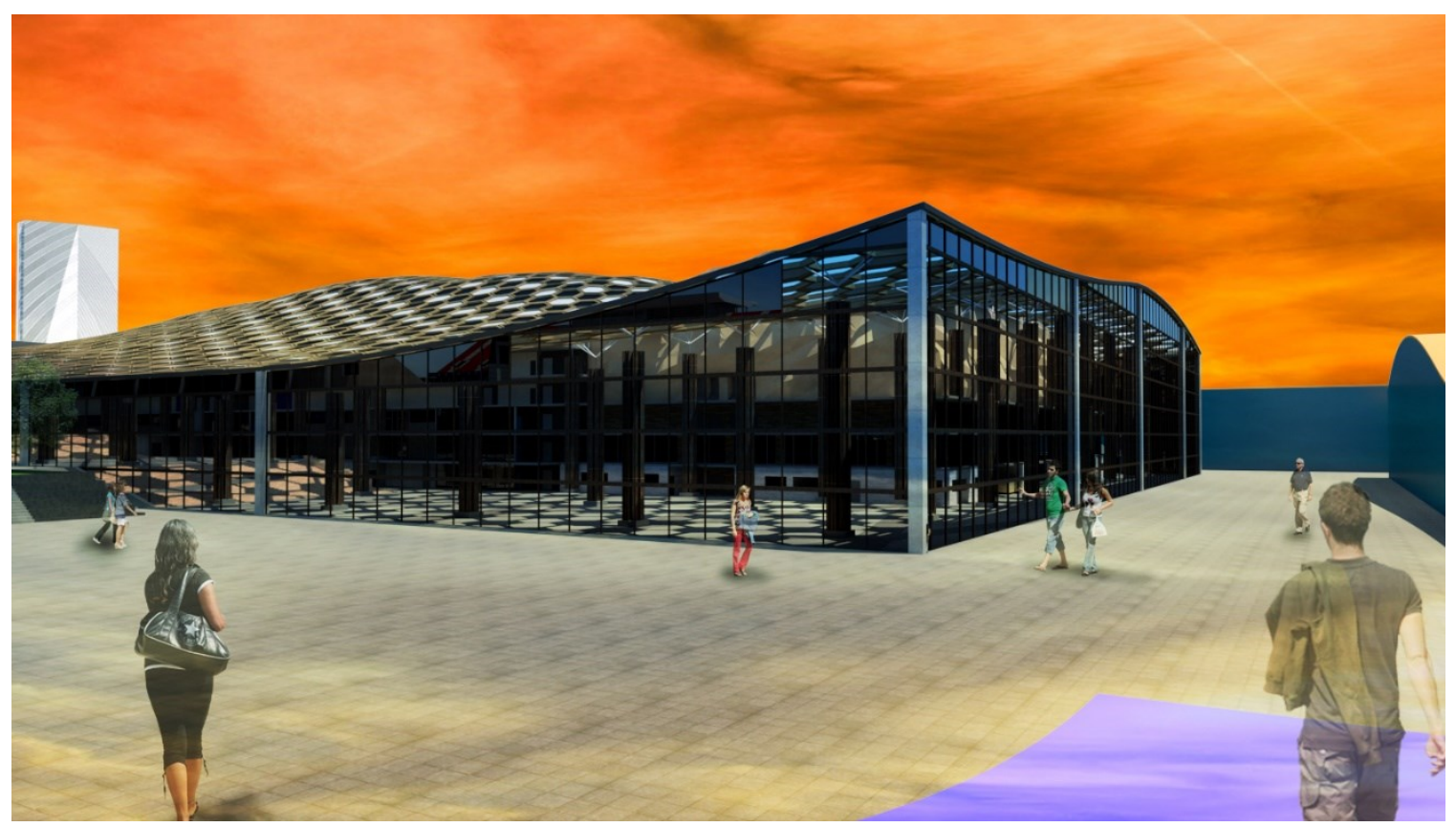

Figure 3-25: Closed folding glazing summer view 


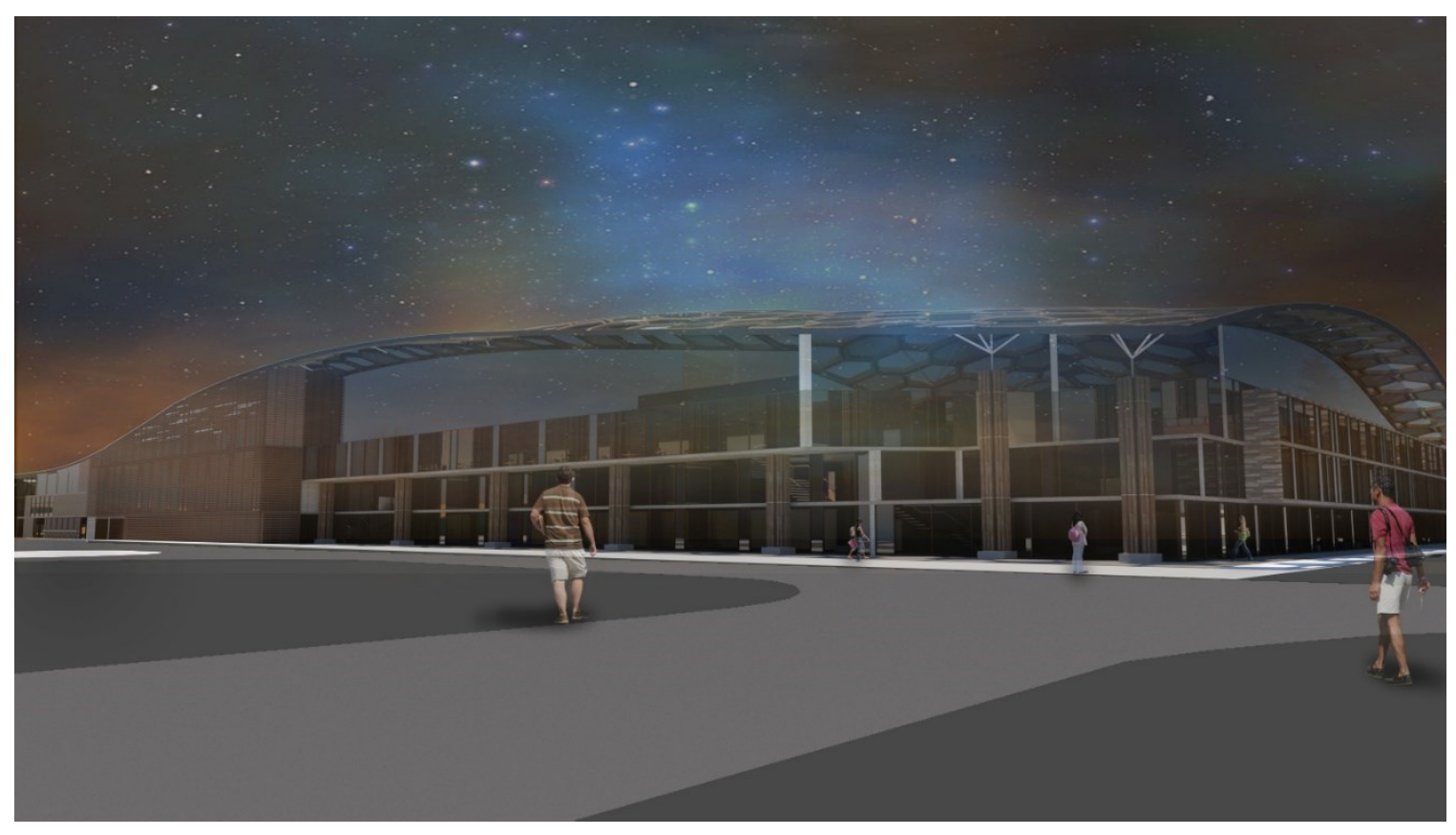

Figure 3-26: Front entry 
Figure 3-27: Floor plan 1

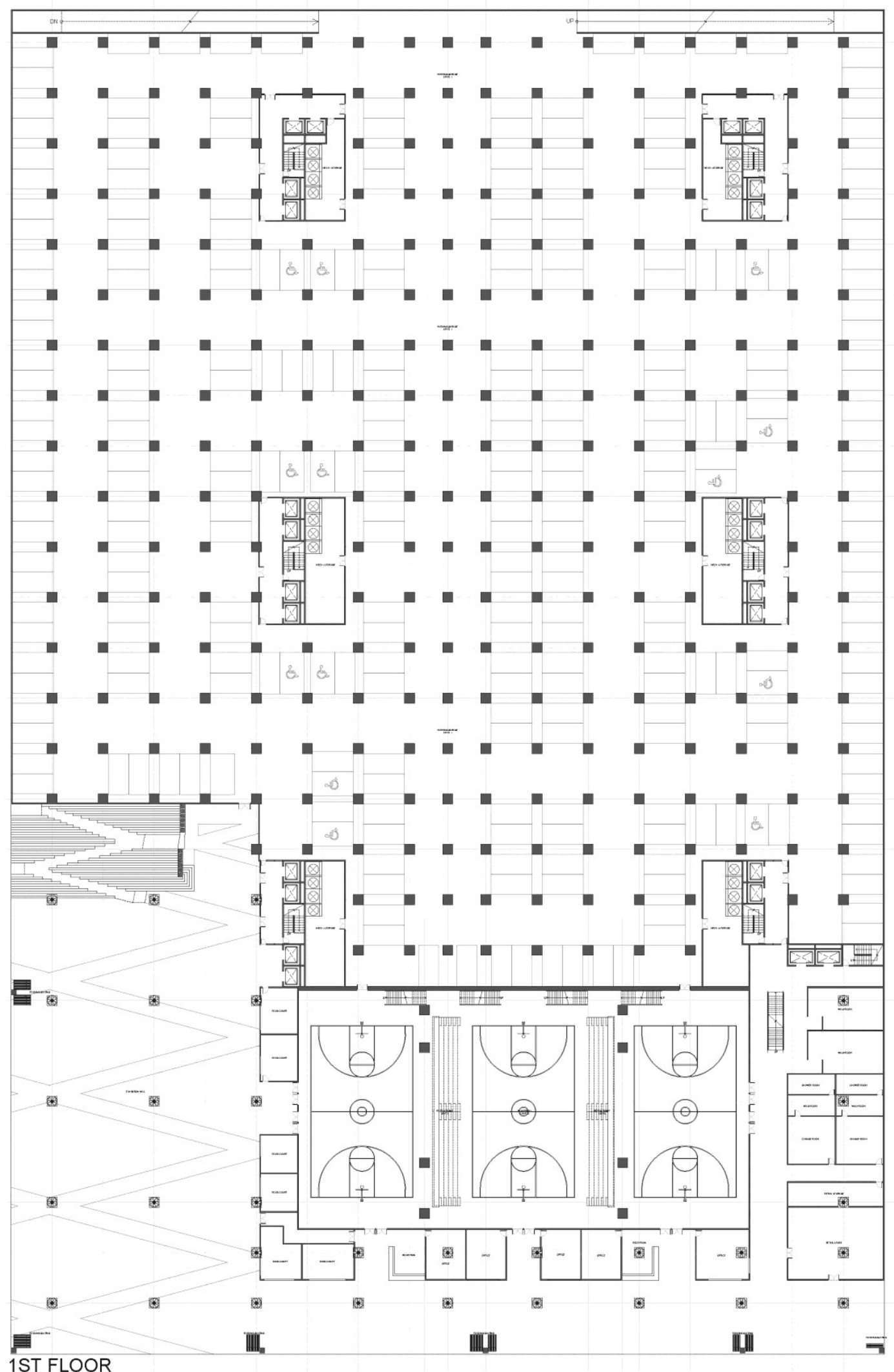


Figure 3-28: Floor plan 2

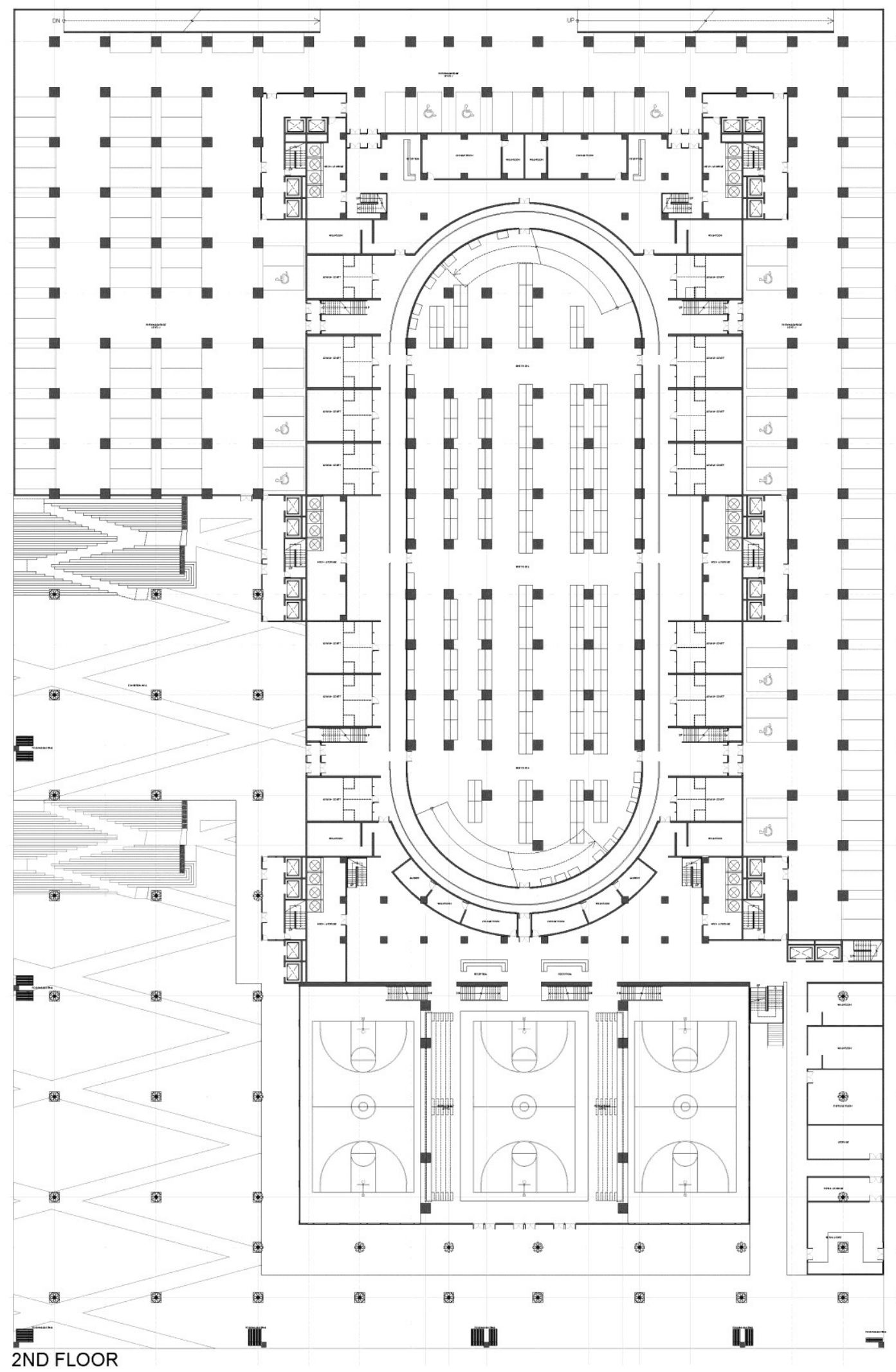


Figure 3-29: Floor plan 3

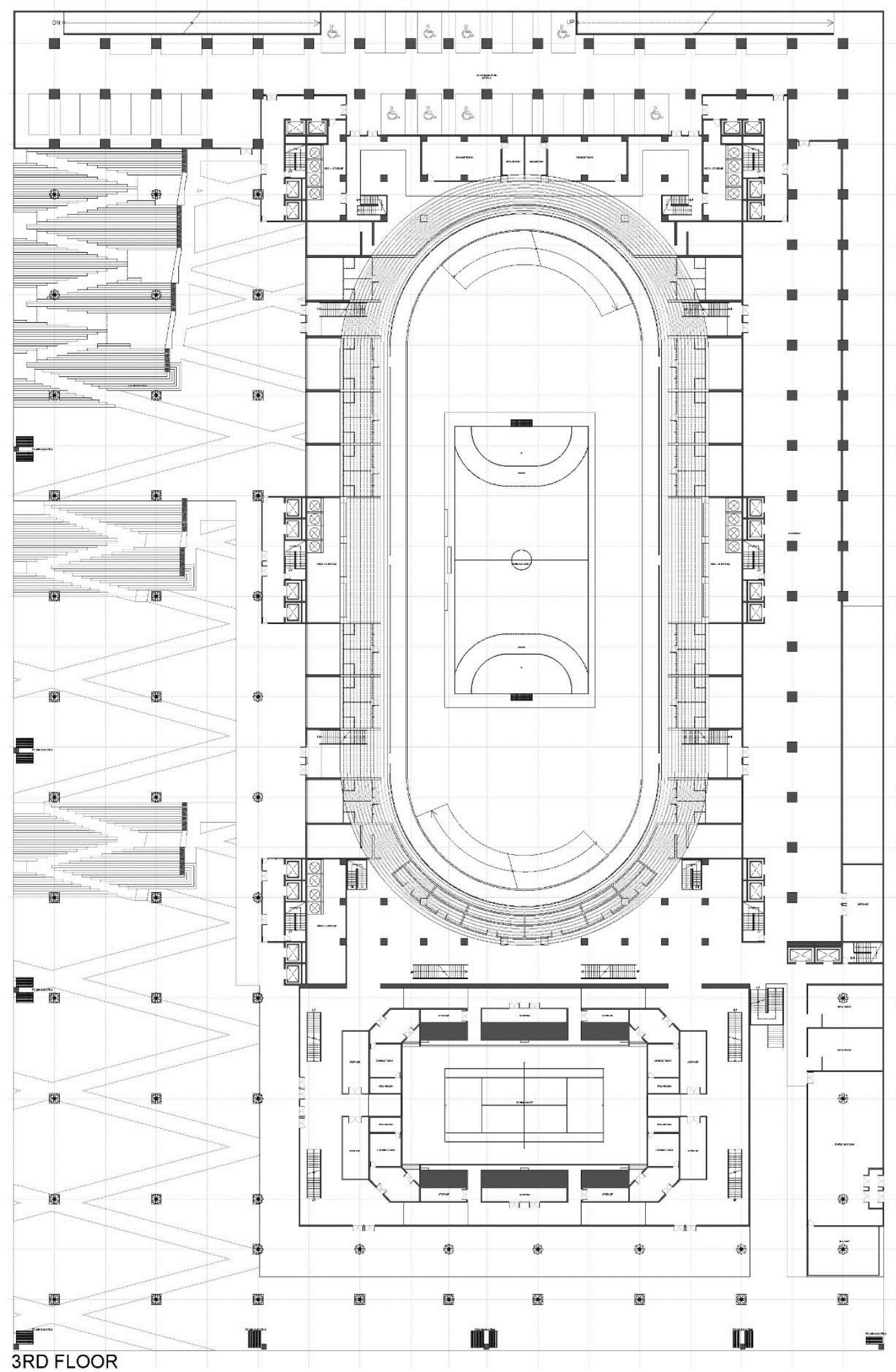


Figure 3-30: Floor plan 4

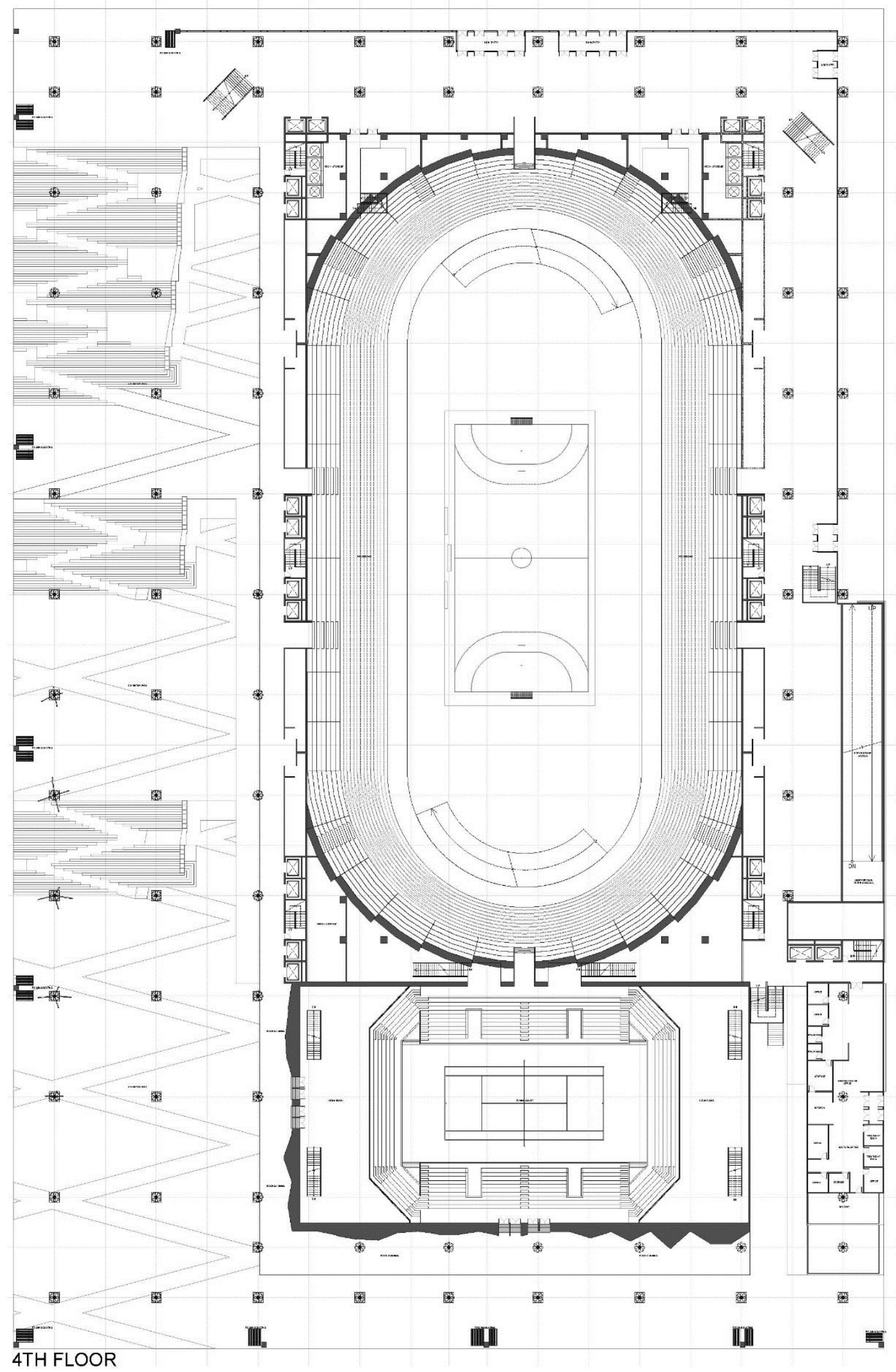


Figure 3-31: Floor plan 5

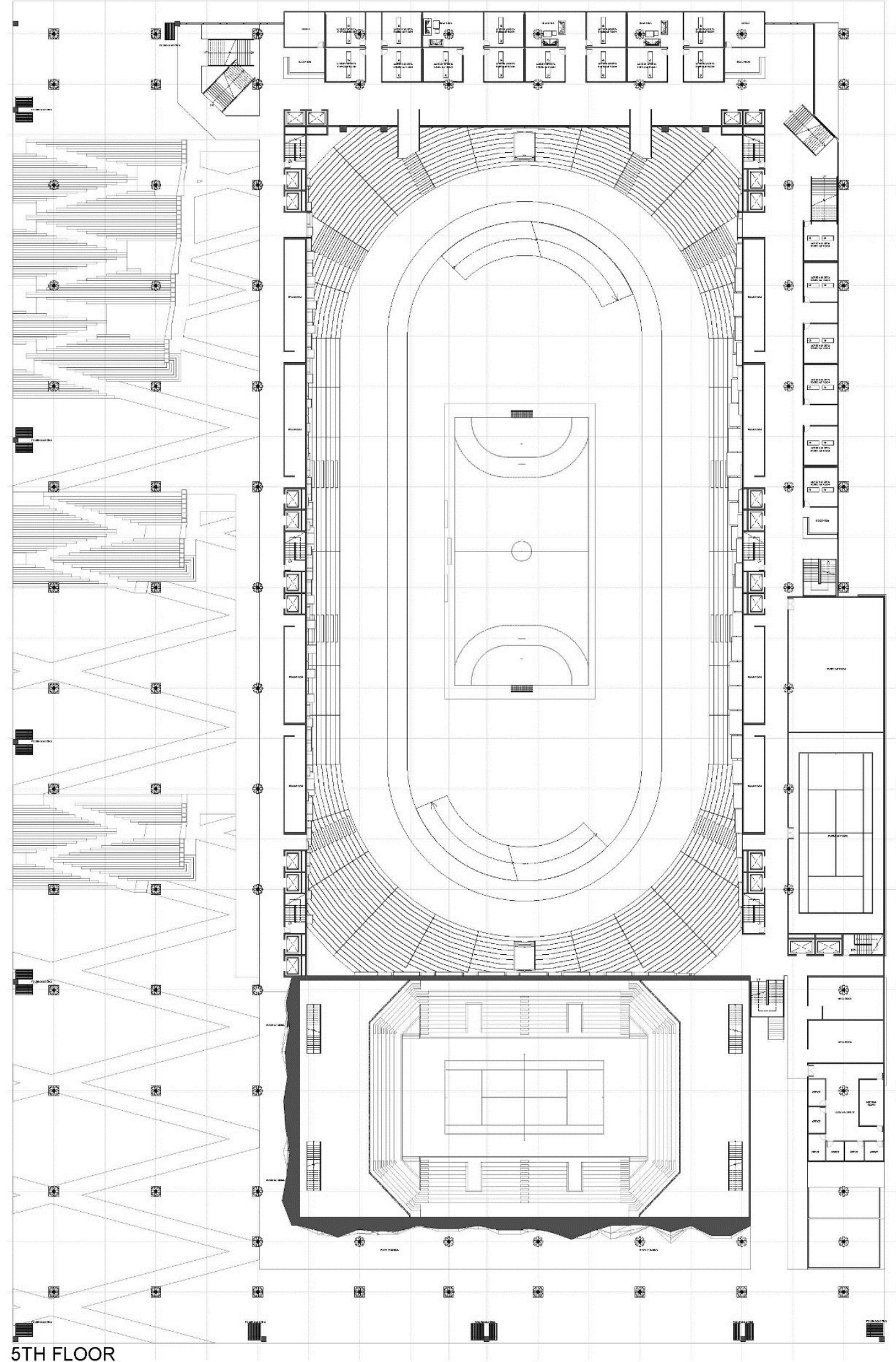


Figure 3-32: Floor plan 6

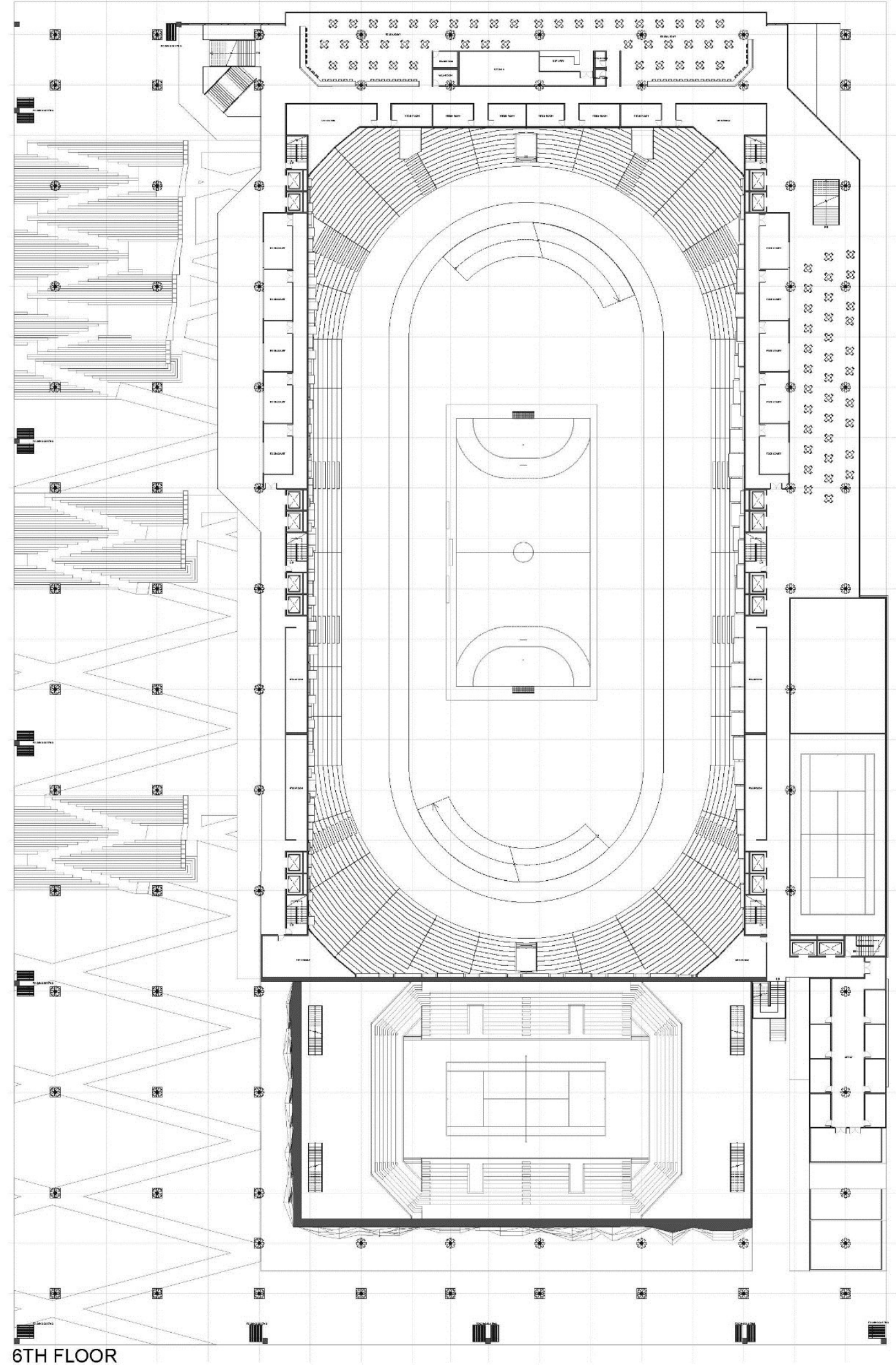


Figure 3-33: Roof plan

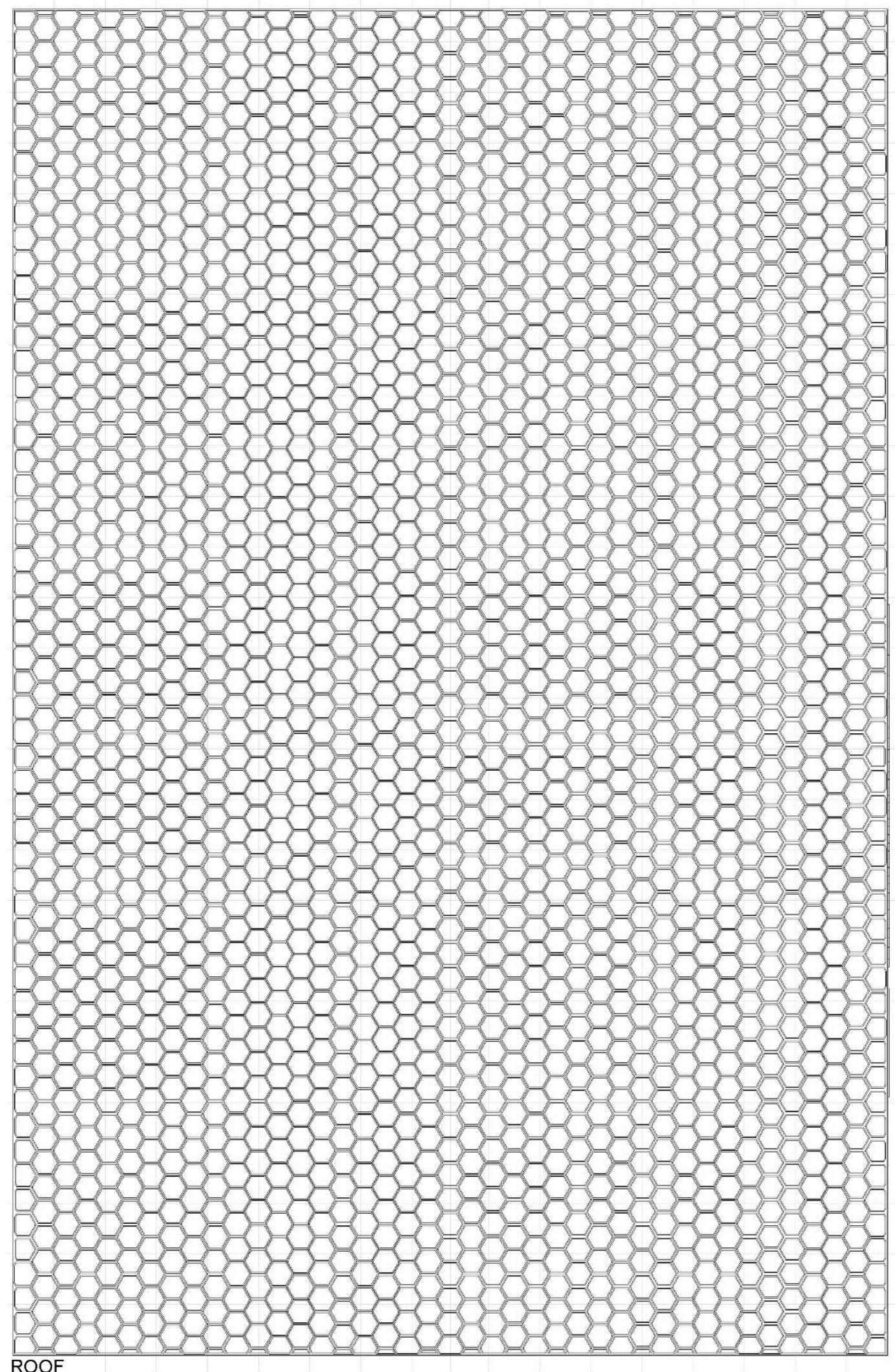




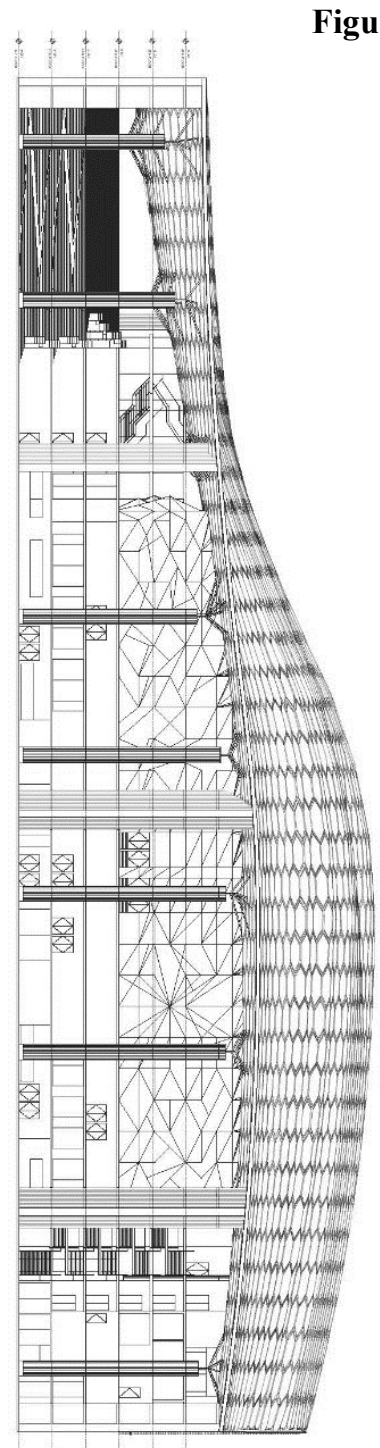

igure 3-34: Section / Elevation
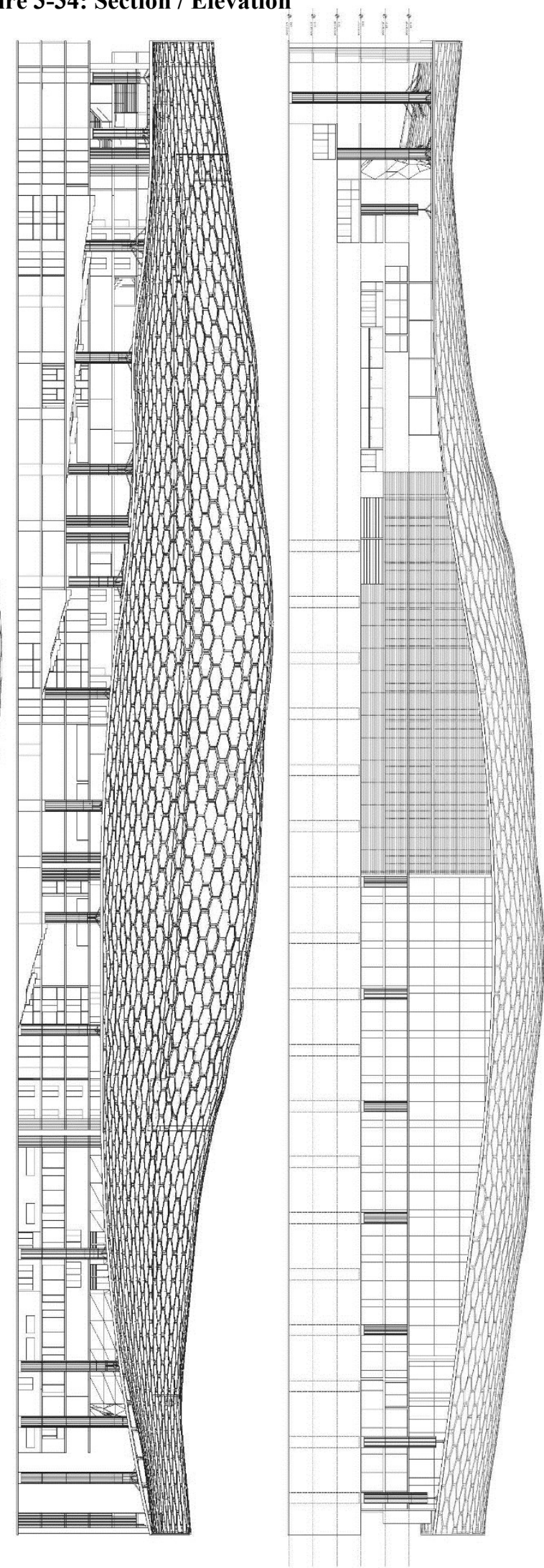
Figure 3-35: Column Elevation / Section

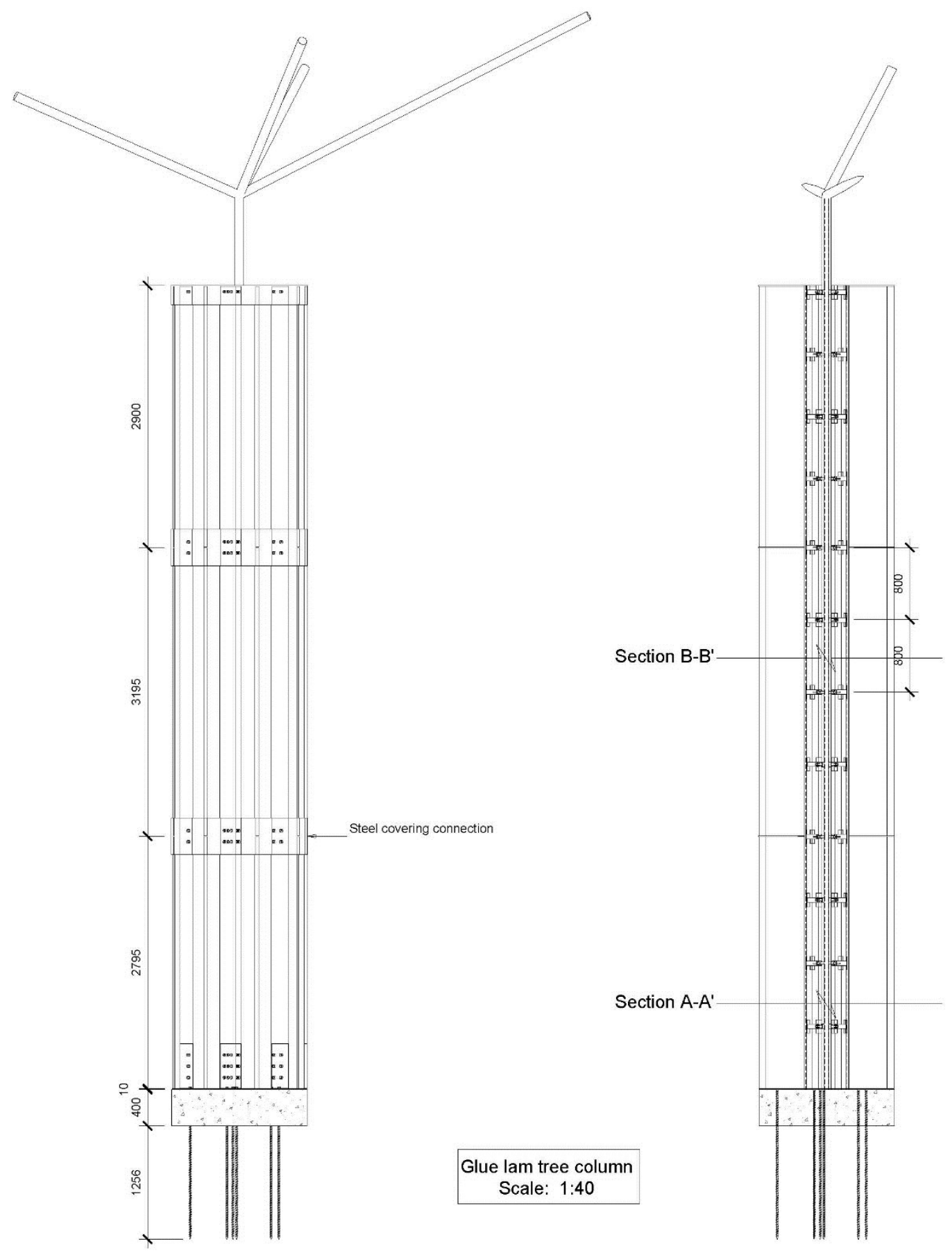




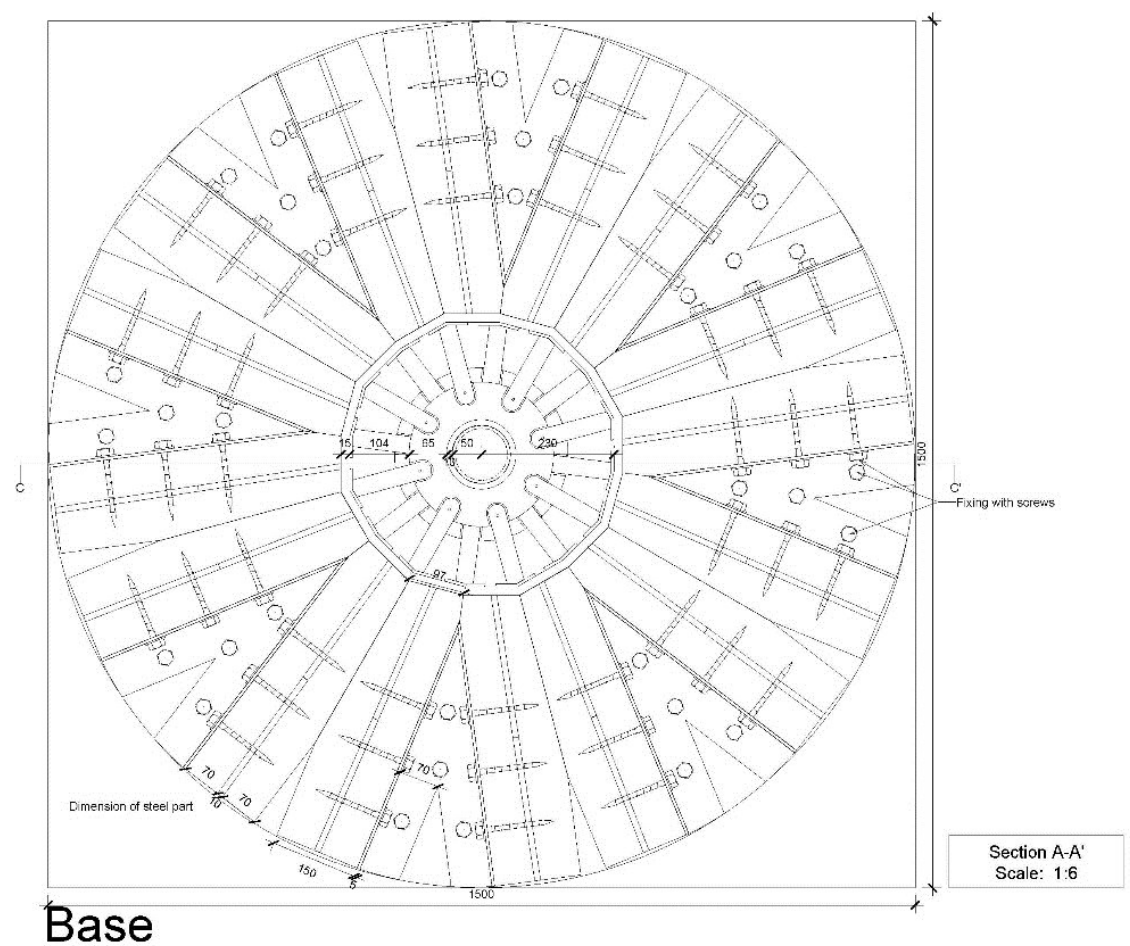

Figure 3-36: Column Plan 1

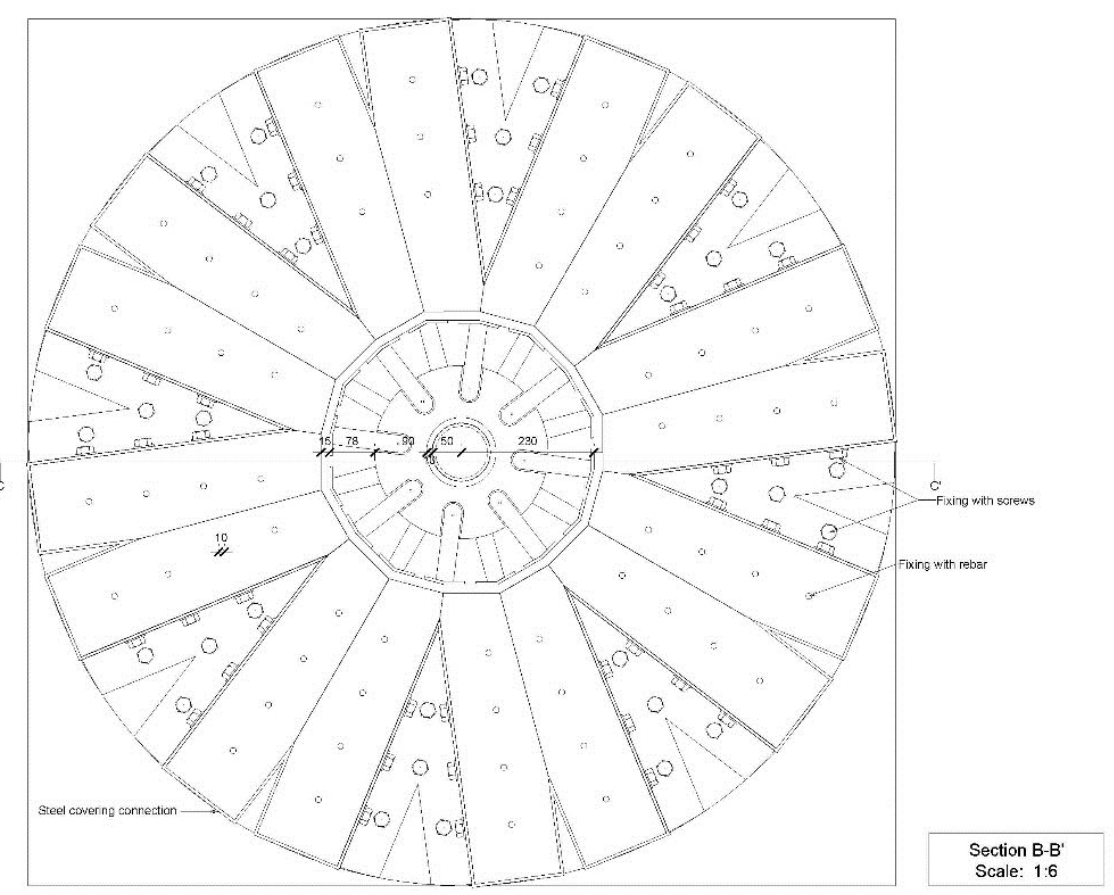

Middle

Figure 3-37: Column plan 2 


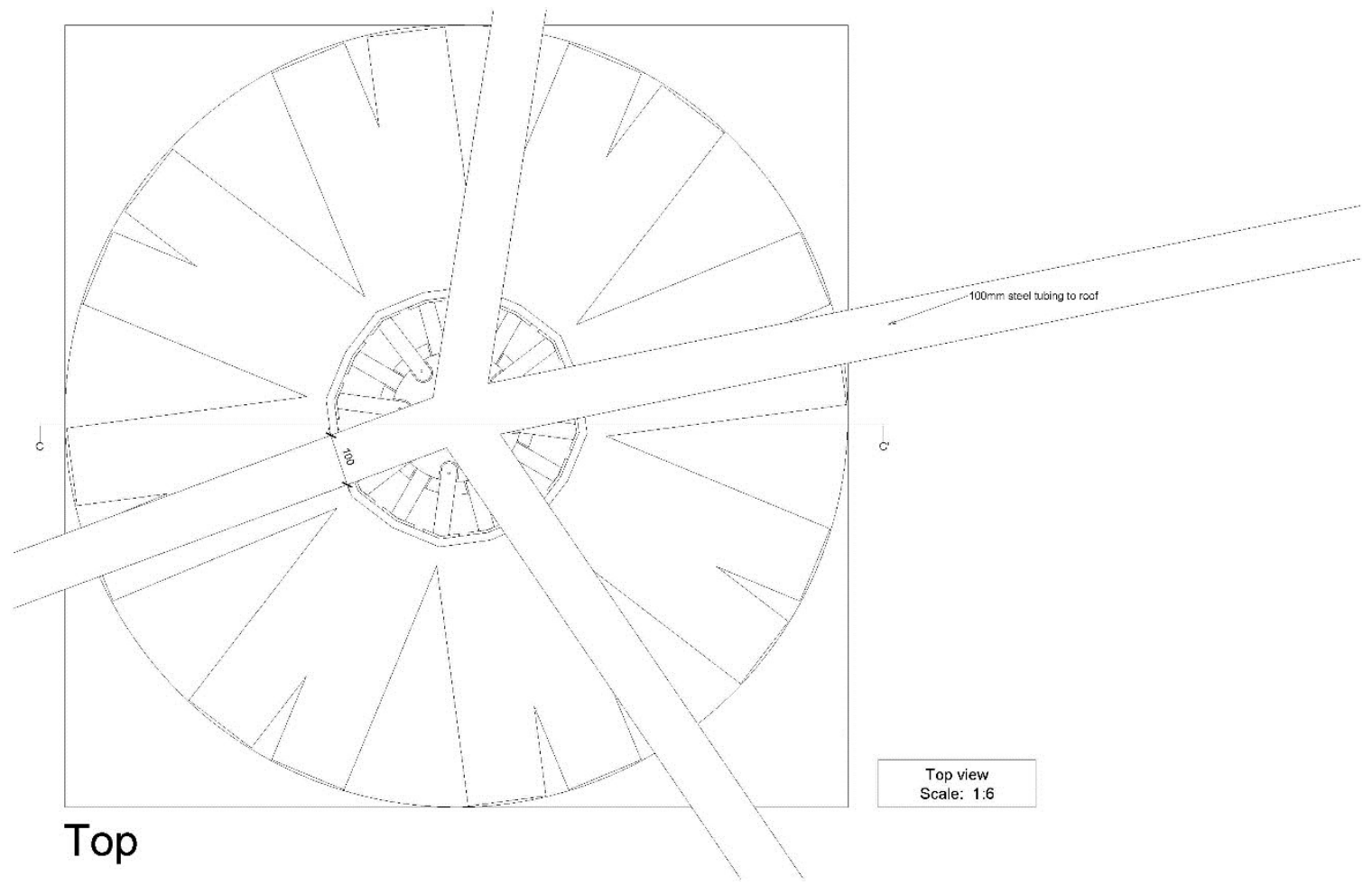

Figure 3-38: Column plan 3

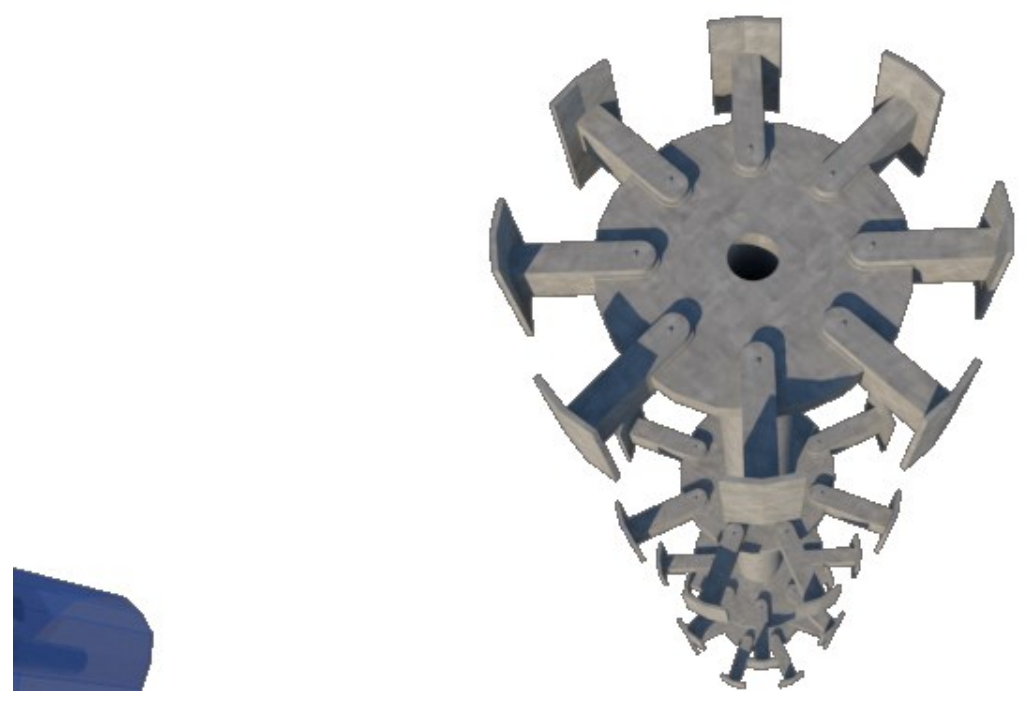

Figure 3-39: Column detail 1 


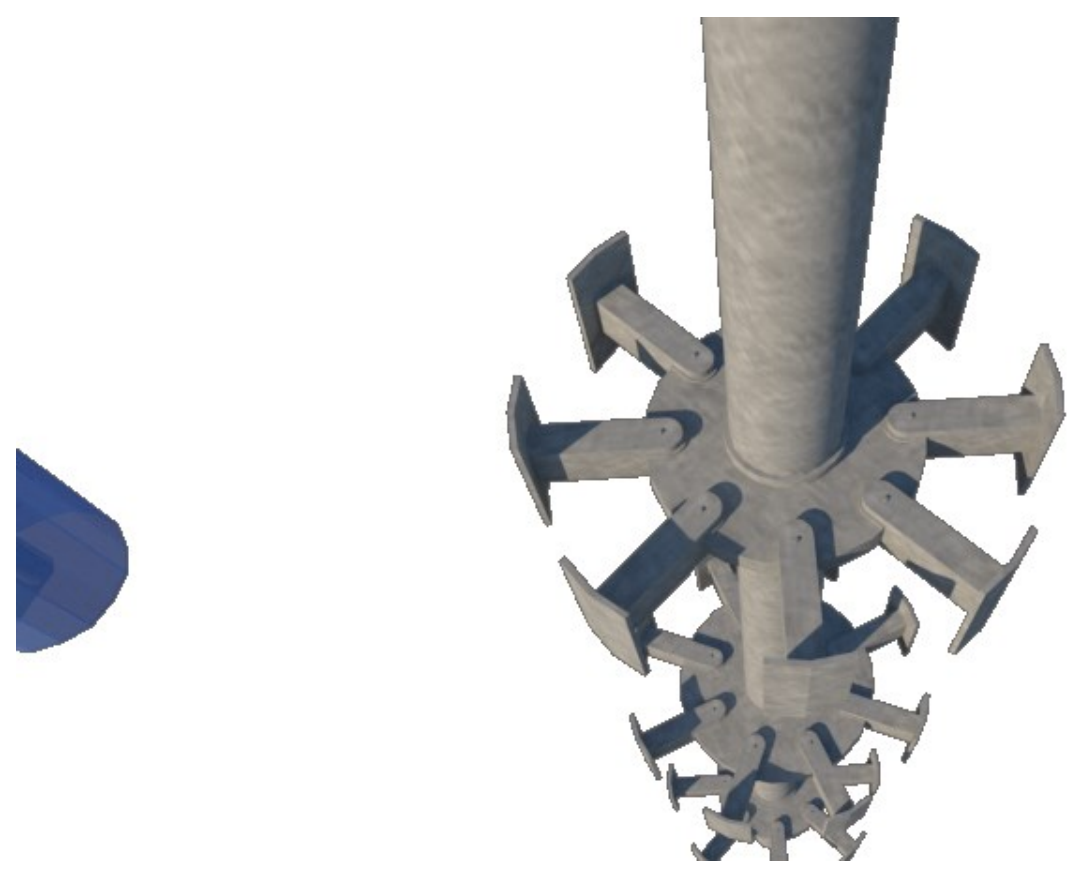

Figure 3-40: Column detail 2

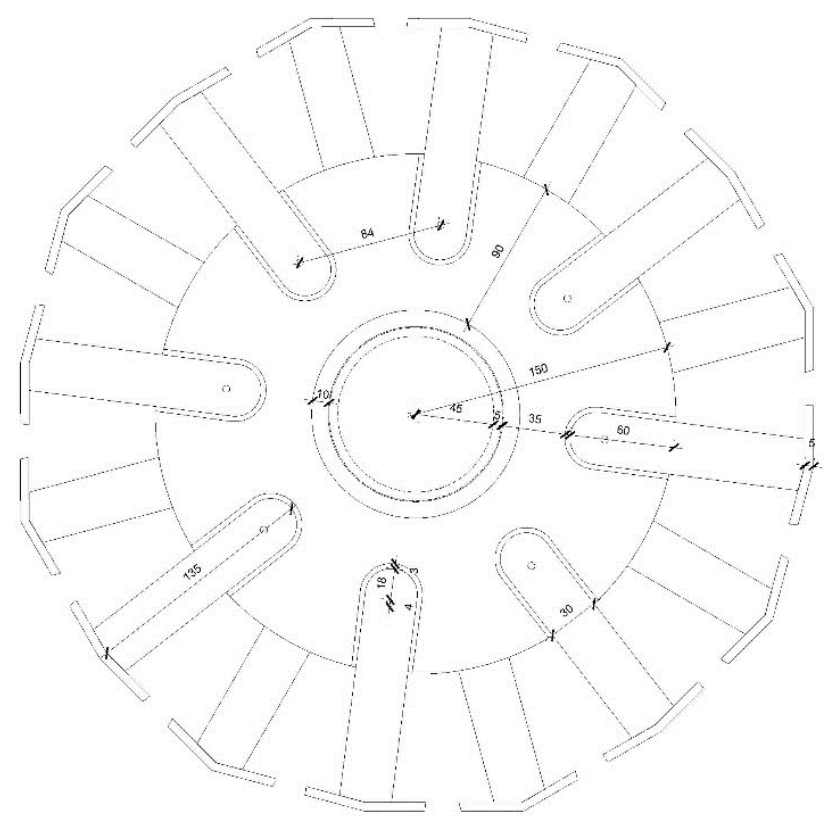

Figure 3-41: Column detail with dimension 1 


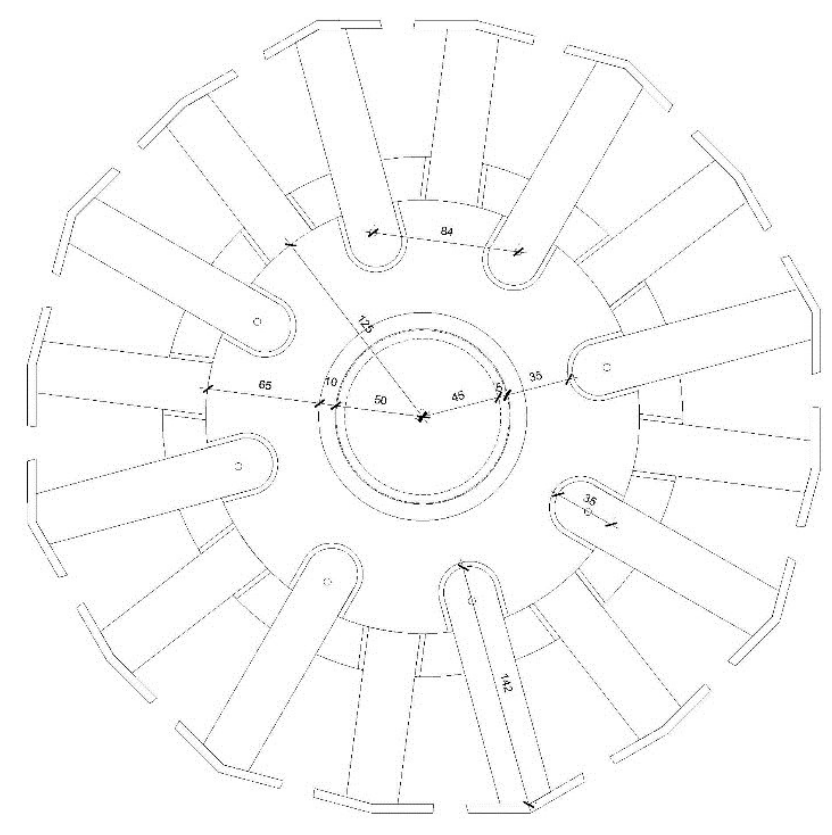

Ring connection 2

Scale: $1: 2$

Figure 3-42: Column detail with dimension 2

\subsection{Looking Ahead}

On July $16^{\text {th }} 2017$, the city of Toronto hosted the North American Indigenous Games. ${ }^{28}$ The venues for the events were held in different areas of the city, including North York and Scarborough. These games and their venues were part of the city's strategy for a 2028 or 2032 Olympic Games bid. The city attempted to demonstrate its capacity to host mega-events through a number of strategies. Moreover, USA, Canada and Mexico made a joint bid for --the United FIFA World Cup 2026 - went forward on April 10, 2017..$^{29}$ If this

\footnotetext{
28 "Toronto 2017 North American Indigenous Games | NAIG." Indigenous Games 2017. Accessed April 13, 2017. http://naig2017.to/.

29 "United 2026: The 2026 FIFA World Cup." United 2026: The 2026 FIFA World Cup. Accessed September 21, 2018. http://united2026.com/.
} 
sporting event happens the site has a much higher chance of being developed for a future sports related program.

\section{Chapter: Conclusion}

In recent years, mega-sporting events and their planning organizations have been plagued by accusations (and evidence) of corruption and scandal. Planning committees for candidate cities have at times resorted to bribes in order to be selected for a particular event, brushing over or hiding financial corruption, as well as - as recently seen in the Middle East - human rights abuses during the construction process. Engaging with the broader public in a transparent and honest fashion is essential in securing community support for these often-significant investments. This includes the necessary planning on how mega-sport investments and infrastructure can directly benefit locals as well as visitors.

The Athens Olympics demonstrated how challenging and problematic a megasporting event can be. Qatar risks the same in its World Cup planning and implementation. On the other hand, the City of Toronto and its current preparations make it a strong candidate for future mega-sports events. It may take time, but the effort will be worth it. While these may be very specific events with very specific space and equipment needs, the infrastructure that supports them - both during and after - must be centered around the public and on the local community that lives with its urban implications. 


\section{Bibliography}

- Swaddling, Judith. The Ancient Olympic Games. 2nd ed. Austin: University of Texas Press, 2008.

- Bernstock, Penny. Olympic housing: a critical review of London 2012s legacy. Farnham, Surrey: Ashgate, 2014.

- Pitts, Adrian C., and Hanwen Liao. Sustainable Olympic design and urban development. Milton Park, Abingdon: Routledge, 2009.

- Hill, Christopher R. Olympic politics:. 2nd ed. Manchester: Manchester University Press, 1996.

- Kassens, Eva. Planning Olympic legacies: transport dreams and urban realities. Milton Park, Abingdon, Oxon: Routledge, 2012.

- Hoberman, John M. The Olympic crisis: sport, politics and the moral order. New Rochelle, NY: Caratzas, 1986.

- Burbank, Matthew J., Gregory D. Andranovich, and Charles H. Heying. Olympic dreams: The impact of mega-events on local politics. Boulder, CO.: Lynne Rienner Publishers, 2001. 
- Schittich, Christian (Edt). Holz = wood: best of Detail. München: Institut für internationale Architektur-Dokumentation, 2014.

- Sebestyen, Gyula Pollington Christopher. New Architecture and Technology. S.1.: Routledge, 2016.

- Wilkinson, Chris. Supersheds: the architecture of long-span, large volume buildings. 2nd ed. Oxford: Butterworth Architecture, 1996.

- Sheard, Rod. Sports Architecture. S.1.: Crc Press, 2016.

- Lee, Uje. Cultural Facility-Three approaches: woood and architecture. Series 344. Seoul: C3, 2013.

- Lee, Uje. Minor-works: Urban How: Virtuous-urban pieces: civic engagement. Series 347. Seoul: C3, 2013.

- Lee, Uje. Dwelling Shift. Series 348. Seoul: C3, 2013.

- "Athens 1896." International Olympic Committee. February 22, 2017. Accessed June 20, 2017. https://www.olympic.org/athens-1896. 
- "Rio 2016." International Olympic Committee. September 22, 2017. Accessed October 5, 2017. https://www.olympic.org/rio-2016.

- "PyeongChang 2018." International Olympic Committee. June 12, 2018. Accessed August 5, 2018. https://www.olympic.org/pyeongchang-2018.

- Schlotterbeck, Bianca. "Olympic Cities: Booms and Busts." CNBC. January 19, 2012. Accessed July \& Aug., 2016. http://www.cnbc.com/2012/01/19/Olympic-Cities:-Booms-andBusts.html? slide $=7 \&$ page $=5$

- Rider, David. "No Olympics, but Tory open to other international events." Thestar.com. September 15, 2015. Accessed December 16, 2016. https://www.thestar.com/news/city hall/2015/09/15/its-official-toronto-wont-bidfor-2024-olympics.html.

- Young, Chris, "Toronto's possible Olympics bid met with budget cautions." Sportsnet.ca. Accessed December 16, 2016. https://www.sportsnet.ca/more/torontos-possible-olympic-bid-met-with-budgetcautions/. 
- City of Toronto. "Toronto \& the Toronto Region.". Accessed July 10, 2017. http://www.toronto.ca/city-government/accountability-operations-customerservice/get-involved-how-government-works/toronto-the-toronto-region/

- "About the Pan Am Games." Rowing | Toronto 2015 Pan Am / Parapan Am Games. Accessed November 5, 2015. http://www.toronto2015.org/about-us/pan-am-games.

- "Welcome to Canada's largest entertainment venues." Exhibition Place: Canada's Largest Entertainment Venues. Accessed November 10, 2015. https://www.explace.on.ca/.

- "Exhibition Place.". Accessed November 10, 2015. https://en.wikipedia.org/wiki/Exhibition_Place.

- "Toronto 2017 North American Indigenous Games | NAIG." Indigenous Games 2017. Accessed April 13, 2017. http://naig2017.to/.

- $\quad$ "Olympic Cities: Booms and Busts." CNBC. Accessed July/August 2016. https://www.cnbc.com/2012/01/19/Olympic-Cities:-Booms-and-Busts.html. 
- $\quad$ "Cost of the Olympic Games." Wikipedia. Accessed December 14, 2015. https://en.wikipedia.org/wiki/Cost_of the_Olympic_Games.

- Florida, Richard. "Why Toronto should say No to the Olympics." The Globe and Mail. September 9, 2015. Accessed December 16, 2015. http://www.theglobeandmail.com/globe-debate/why-toronto-should-say-no-tothe-olympics/article26263925/.

- "Parking at Exhibition Place." Parking at Exhibition Place | Exhibition Place. Accessed November 03, 2015. https://www.explace.on.ca/visiting/getting-here/parking-at-exhibition-place.

- "Forests." Natural Resources Canada. November 15, 2017. Accessed November 5,2015 http://www.nrcan.gc.ca/forests.

- "Stadium History." BMO Field. Accessed November 03, 2015. https://bmofield.com/venue-info/stadium-history/.

- "Coca-Cola Coliseum." Wikipedia. June 07, 2015. Accessed November 03, 2015. https://en.wikipedia.org/wiki/Coca-Cola_Coliseum. 
- "Venues." Ron Baird | Exhibition Place. Accessed November 03, 2015. https://www.explace.on.ca/venues.

- "Kyoto Protocol - Targets for the First Commitment Period." UNFCCC. Accessed June 15, 2016. https://unfccc.int/process/the-kyoto-protocol.

- "Emerald Ash Borer." Natural Resources Canada. Accessed May 05, 2016. https://www.nrcan.gc.ca/forests/fire-insects-disturbances/top-insects/13377.

• "United 2026: The 2026 FIFA World Cup." United 2026: The 2026 FIFA World Cup. Accessed September 21, 2018. http://united2026.com/.

- "How Beijing used rockets to keep opening ceremony dry." The Independent. Accessed August, 2016. https://www.independent.co.uk/sport/olympics/howbeijing-used-rockets-to-keep-opening-ceremony-dry-890294.html. 